\title{
Quantifying the Net Environmental Impact of Using loT to Support Circular Strategies-The Case of Heavy-Duty Truck Tires in Sweden
}

\author{
Emilia Ingemarsdotter ${ }^{1}$ (D) Derek Diener ${ }^{2} \cdot$ Simon Andersson $^{3} \cdot$ Christian Jonasson $^{2}$. \\ Ann-Charlotte Mellquist ${ }^{2} \cdot$ Thomas Nyström $^{2} \cdot$ Ella Jamsin $^{1} \cdot$ Ruud Balkenende ${ }^{1}$
}

Received: 31 October 2020 / Accepted: 4 February 2021 / Published online: 20 May 2021

(C) The Author(s) 2021

\begin{abstract}
The idea of leveraging the Internet of Things (IoT) to support strategies in line with the circular economy (CE) has been gaining traction in literature. However, previous work has predominantly focused on the opportunities that these technologies can bring, and few studies have critically assessed the environmental viability of the proposed strategies. In this study, we assess the net environmental impact of IoT-enabled circular strategies in the specific case of truck tires in the Swedish context, in order to gain insight into when and how it makes environmental sense to embed IoT hardware into products to support circular strategies. We quantify (1) the potential environmental savings in the different life cycle phases made possible through access to sensor data, and (2) the environmental impact from the added technology needed to provide and process the data. Life cycle assessment (LCA) is used to evaluate the difference in impact between the current state and an 'IoT scenario'. We find that the IoT scenario gives a $4 \%$ lower weighted life cycle impact than the current state. Through sensitivity analysis, we show that the conclusions are sensitive to assumptions made about the expected benefits of adding IoT, which depend on the technological context as well as the current and IoT-induced behavior of stakeholders along the product life cycle. The results are also sensitive to assumptions about the environmental impact of the IoT hardware components, implying that design decisions at this level can be important for ensuring a net environmental impact reduction from IoT-enabled circular strategies.
\end{abstract}

Keywords Circular economy · Internet of Things · Digitalization · Life cycle assessment . Retreading

Emilia Ingemarsdotter

e.k.ingemarsdotter@tudelft.nl

Extended author information available on the last page of the article 


\section{Introduction}

By connecting products to the internet, and monitoring them over time, actors along the supply chain can get insights into products' performance and condition in the field. This information can be used to support strategies that are in line with the vision of a circular economy $(\mathrm{CE})$, such as efficiency measures in the use phase, product lifetime extension, reuse, remanufacturing, and recycling [1]. Several recent publications focus on these opportunities, and how companies might use them to their advantage (e.g., [2-4]).

However, few studies have investigated the net environmental impact of such IoT-enabled circular strategies, accounting for the potential environmental savings as well as the obvious environmental downsides of IoT, such as increased use of toxic substances and/or critical raw materials, energy use for data collection and processing, and increased amounts of electronic waste. As of yet, literature about the environmental impact of circular strategies (e.g., [5-7]) is largely separated from the literature about the environmental impact of IoT-related components and technologies, such as RFID tags [8], wireless sensor networks [9], mobile networks $[10,11]$, and cloud-level data storage and processing [12-16]. Combining these two fields is important in order to understand the net impact of IoT-enabled circular strategies and to support companies in making more conscious decisions about if and how to develop an IoT solution to their CE problem.

Through a dedicated search for literature focusing on the environmental effects of IoT in the context of $\mathrm{CE}$, a small number of previous studies were identified. Lelah et al. [17] studied the environmental consequences of an IoT solution that is aimed at reducing unnecessary transportation in a glass waste collection system. They compare the improvements gained from reduced transport to the added impact from using 'machine-to-machine' technologies. They point out that the production of the IoT system leads to increased impact in some impact categories, most notably raw material depletion and hazardous waste production, while impacts related to energy depletion, global warming, and air toxicity decrease. They also found that the production and use of the telecommunications infrastructure needed to support the IoT system did not significantly affect the net environmental impact.

Bonvoisin et al. [18] presented a framework for evaluating the environmental impact of 'optimization services' enabled by ICT. They applied this framework to the case of smart waste bins, and found, like Lelah et al. [17], that for global warming potential, the benefits outweighed the drawbacks, but for raw material depletion the IoT case performed worse. They discuss that there is often a risk for 'impact shifting' between impact categories when introducing IoT-enabled optimizations, and emphasize the importance of including multiple impact categories in the assessment.

Kumar and Mani [19] estimated the net energy conservation that could be achieved from installing occupancy sensors in office buildings so that the light automatically switches off when nobody is in the room. They concluded that adding the sensors did not conserve energy, due to the high energy requirements in the life cycle of occupancy sensors. In a more recent conference paper, Dekoninck and Barbaccia [20] conducted a 'streamlined LCA' of a smart fridge, only focusing on the use phase and using global warming potential (GWP) as the sole indicator for environmental impact. They found that the smart fridge was environmentally preferable since the use-phase GWP impact associated with adding IoT (mainly caused by energy use for browsing the internet) was smaller than the savings achieved through reduced food waste and increased levels of online grocery shopping 
(rather than traveling to the store). Moreover, they noted that the use-phase impact reduction depended strongly on the ability of the 'smart system' to steer user behavior in a more sustainable direction, mainly to reduce food waste. Yuli et al. [21] studied the net GWP reduction from an IoT-enabled irrigation system compared to a conventional irrigation system and concluded that the savings outweighed the impacts. The savings were estimated by the potential for the IoT solution to reduce water and fertilizer consumption in the irrigation system's use phase, while added impacts from the IoT solution itself (sensors, control unit, and gateway) were analyzed cradle-to-grave.

The available literature also presents recommendations for how designers might increase the net environmental benefit of the respective IoT solutions, both how to maximize the environmental savings enabled by the IoT solution and how to minimize the environmental impacts from the IoT solution itself. Focusing on the first aspect, i.e., how to achieve environmental savings, Dekoninck and Barbaccia [20] emphasize the need to design user interfaces that can actually change user behavior. Kumar and Mani [19] recommend prioritizing use contexts for which the potential for impact reduction is high. In the case of indoor lighting systems, they recommend only using occupancy sensors in areas with low occupancy levels, such as corridors and restrooms.

With regards to minimizing the impact from the IoT solution itself, Lelah et al. [17] suggest that designers should choose small and low-impact components. Moreover, they discuss that the impact could be reduced if different IoT services in the city (e.g., smart waste collection, smart lighting, and water monitoring systems) would share the same gateways. Bonvoisin et al. [18] recommend a closed-loop approach to electronics design, focusing on longevity, reusability, and remanufacturability of IoT components. Moreover, they highlight the need to apply eco-design thinking to ICT infrastructure and to the generation of information, including data collection, transmission, and analysis. Kumar and Mani [19] recommend local production of sensors, low-impact packaging for sensors, improved reuse of electronic components, and improved recycling techniques for electronics. Dekoninck and Barbaccia [20] note that the onfridge web-browsing system should be designed carefully to minimize added impacts from internet browsing.

We note that the current understanding of the net environmental impact of IoT-enabled circular strategies builds on a small number of papers and a limited range of products. Moreover, none of the identified papers address the potential of IoT solutions to extend the lifetime of products, or to increase their recovery rate. Since product lifetime extension and post-use recovery are core strategies in the $\mathrm{CE}$ and since IoT is seen as an enabler for such strategies [1-3], we see a need for additional studies that take these aspects into account.

This paper is aimed at addressing some of the abovementioned research gaps by posing the following research question: Which factors are important to ensure a net reduction of environmental impact from IoT-enabled circular strategies? We study the specific case of heavy-duty truck tires in the Swedish context, for which opportunities have been identified for IoT to support fuel efficiency, longer tire lifetimes, and a larger share of used tires being retreaded, i.e., remanufactured through replacement of the outermost part of the tire (the tread) [22-24]. We assess the net environmental effect of using IoT to support circular strategies, considering all life cycle stages of the tires as well as the IoT components. We estimate the environmental improvements that can be achieved by using IoT, as well as the added impact from the technology itself, and compare this 'IoT scenario' to the current state. In order to identify potential 'impact shifting', impact is measured across a range of impact categories. 


\section{Methodology}

This study builds on insights collected during a research project which gathered stakeholders from a truck tire business ecosystem in Sweden with the aim to investigate what a future circular ecosystem for heavy-duty truck tires could look like. Results from the project have previously been presented in [22-24]

In this study, Life Cycle Assessment (LCA) is used to compare the environmental impact of heavy-duty truck tires in the current Swedish system with a scenario in which IoT is used to support improved circularity. As presented in the ISO14040 standard [25], "LCA studies the environmental aspects and potential impacts throughout a product's life (i.e. cradle-to-grave) from raw material acquisition through production, use, and disposal. The general categories of environmental impacts needing consideration include resource use, human health, and ecological consequences." As such, LCA supports the learning and understanding of environmental problems caused by product systems, from raw materials to end of life [26].

\section{Goal}

The goal of the LCA is to compare the environmental impact of heavy-duty truck tires in the current Swedish system with an 'IoT scenario' in which circular improvements are enabled by IoT. The IoT scenario is modeled as a hypothetical scenario in the present-time tire system. As such, the model does not include a temporal shift between the two alternatives. The IoT scenario includes the three following opportunities for IoT to support circular strategies: (1) IoT supports more optimal tire pressure during use and thereby reduces fuel consumption, (2) IoT allows for prolonged tire use times, based on a better understanding of the individual tire's condition as well as minimized wear due to improved pressure monitoring, and (3) IoT increases the rate of retreading through more accurate assessment of the 'reatreadability' of used tires.

\section{Data Sources, Software, and Assessment Method}

The software SimaPro 9.0 [27] is used to model the system. The Ecoinvent database v.3.5 [28] is used as the main source of inventory data. Modeling choices about tires are partly based on literature and partly on direct communication with stakeholders in the Swedish tire system: a truck manufacturer, a retreading company, and a recycling company. Assumptions about the components included in the IoT solution (in the IoT scenario) are based on results from the project detailed in [23], in which different sensor systems for monitoring tire condition were tested. Data about the weight of different components in the Tire Pressure Monitoring System (TPMS) is collected from a TPMS manufacturer [29]. Data about the composition of RFID tags and about the impact of data transfer and processing is collected from previous literature. The data source for each modeling choice is specified in Data collection and modeling.

All assumptions come with a level of uncertainty, and we deal with this by performing sensitivity analysis to test how the results change by varying key parameters within appropriate uncertainty ranges. The uncertainty ranges are specified per parameter in Data collection and modeling.

The ReCIPe 2016 method (hierarchist perspective) [30] is used to assess the environmental impact. We present impacts both as a weighted single score and per impact category. The 
ReCIPe 2016 method in SimaPro 9.0 includes global normalization factors for the reference year 2010 and weighting sets copied from ReCiPe 2008 [31].

\section{Functional Unit}

The function provided by truck tires is that they enable a truck to drive a certain distance. According to the truck manufacturer, two types of trucks are commonly used in the Swedish system: 'tractors/semi-trailers' (10 tires/truck) and 'trucks with trailer' (24 tires/truck). In our model, we assume that the tires are used on a 'tractor/semi-trailer,' but we also include the 'truck with trailer' option in our sensitivity analysis. According to the truck manufacturer, the average yearly driving distance for a truck is $2 \cdot 10^{5} \mathrm{~km}$. Given that a 'tractor/semi-trailer' has 10 tires, we use a reference distance of $2 \cdot 10^{6}$ 'tire-kilometers' for calculating the impacts.

\section{Scope and System Diagram}

Fig. 1 presents a system diagram describing the scope of the LCA and the flow of materials needed to enable the function provided by the tires. We consider the whole life cycle of the tires, from production to end of life, including retreading and multiple use phases. We also include the production of the treads added in retreading, as well as the production, use, and

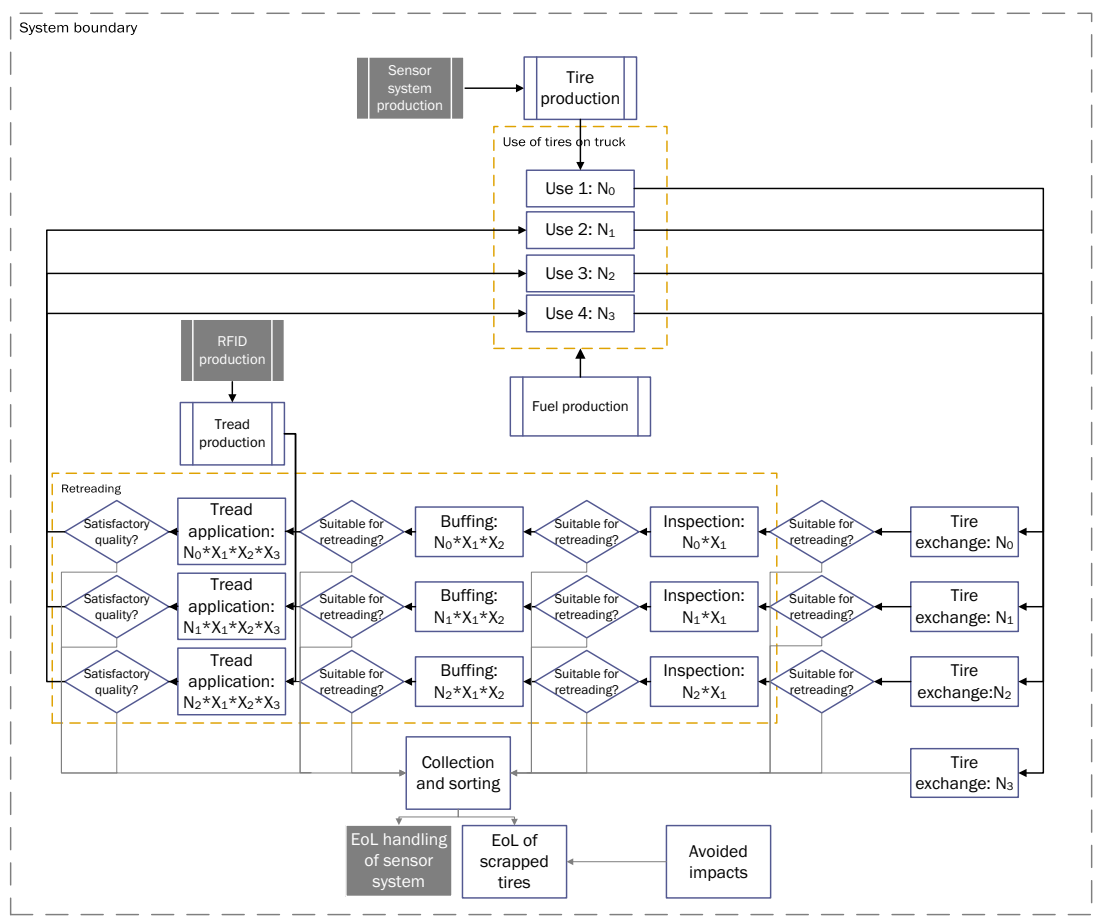

Fig. 1: System diagram. For readability, arrows going to EoL processes have a lighter color. Filled grey boxes are IoT specific, and thereby only included in the IoT scenario. Transportation steps are not shown in the diagram, but are included in the analysis. 
disposal of IoT hardware. Impact from the fuel used by the truck is included 'well-to-wheel'. New tires are assumed to be produced somewhere in Europe, and transported to a hauler company in Sweden. Tires deemed unsuitable for retreading are sent to end of life (EoL) management (detailed in Data Collection and Modeling of the Tire's End of Life in the Appendix). The grey boxes in the system diagram are IoT-specific and are therefore only included in the IoT scenario.

The scope does not include:

- The production of machines used in the tire life cycle, e.g., in manufacturing, retreading, or recycling.

- The production of data transmission infrastructure or servers in data centers where the data is processed.

- Emissions from tire maintenance activities (e.g., transport to service point).

- Packaging.

- Personnel-related emissions, such as commuting to work.

\section{Multi-functional Processes}

System expansion is used to model the multi-functional EoL processes for tires, i.e., incineration and recycling processes. As an example, the incineration of tires for district heating is multi-functional as it both takes care of the waste tires and produces heat. System expansion deals with multi-functionality by expanding the system under study to include additional functions than initially specified in the functional unit [32]. As such, we assume that the production of heat from the incineration of tires replaces the production of heat from other sources. Hence, the tires receive 'credits' for the avoided emissions which would otherwise have been caused by burning fuel to produce heat. Similarly, the tires receive credits when substituting other materials, e.g., as drainage material in landfills. For transparency, such negative impact numbers ('credits') are presented separately in the results.

\section{Data Collection and Modeling}

\section{Equations Describing System Flows}

Here, we introduce the key equations describing the resource flows in our model, and how they depend on whether IoT is used or not. If the value of a function, $f$, depends on whether IoT is used or not, this is denoted as $f(\mathrm{IoT})$.

In the current Swedish tire system, where retreading takes place up to three times, the reference distance of $2 \cdot 10^{6} \mathrm{~km}\left(D_{\text {tot }}\right)$ is covered by a mix of new tires $\left(N_{0}\right)$ and retreaded tires ( $N_{k}$, where $k=1,2,3$ is the number of times the tire has been retreaded). To calculate $N_{0}, N_{1}, N_{2}$, and $N_{3}$, we start by estimating the share of post-use tires that are currently retreaded, and thus used again, as opposed to being sent to EoL management (material recycling or incineration). Based on discussions with the retreading company, we identify four decision points where post-use tires are sorted as 'retreadable' or 'not retreadable', as shown in Fig. 1. These decision points are: (1) at the tire exchange workshop, (2) at the first inspection point in the retreading process, (3) mid-way through the retreading process, and (4) at the final inspection point after 
the retreading process. Again based on discussions with the retreading company, we estimate the current values for the shares $X_{1}, X_{2}, X_{3}$, and $X_{4}$ of incoming tires which are sorted as 'retreadable' at each decision point. As seen in Eq. 1, the shares $X_{1}, X_{2}, X_{3}$, and $X_{4}$ relate $N_{k}$ to $N_{k+1}$. Moreover, as IoT improves the accuracy of the retreadability assessment (see Goal), the shares $X_{1}, X_{2}, X_{3}$, and $X_{4}$ depend on whether IoT is used or not.

$N_{0}, N_{1}, N_{2}$, and $N_{3}$ can be derived from Eqs. 1 and 2. Here, we have considered the possibility that the distance, $D_{0}$, that a tire can cover before it has to be exchanged is different for new tires compared to retreaded ones. However, we assume that the distance, $D_{1,2,3}$, that a retreaded tire can cover is the same irrespective of the number of retreading cycles. Further, as IoT can delay tire replacement (see Goal), the distance that can be covered by a (new or retreaded) tire depends on whether IoT is used or not.

As seen in Eq. 3, the total volume of fuel that is needed to cover the distance $D_{\text {tot }}$ relates to $N_{0}, N_{1}, N_{2}, N_{3}, D_{0}$, and $D_{1,2,3}$ via the fuel consumption that can be allocated to a new or retreaded tire $\left(\mathrm{FC}_{k}[1 / \mathrm{km}]\right)$. Again, we have considered the possibility that the fuel consumption, $\mathrm{FC}_{0}$, that can be allocated to a new tire is different from that of a retreaded tire. Since the fuel consumption depends on the tire pressure, and since IoT allows for keeping tire pressure at an optimal level (see Goal), the fuel consumption depends on whether IoT is used or not.

$$
\begin{gathered}
N_{k+1}(\mathrm{IoT})[\#]=N_{k}(\mathrm{IoT}) \cdot X_{1}(\mathrm{IoT}) \cdot X_{2}(\mathrm{IoT}) \cdot X_{3}(\mathrm{IoT}) \cdot X_{4}(\mathrm{IoT}) \\
D_{\text {tot }}[\mathrm{km}]=D_{0}(\mathrm{IoT}) \cdot N_{0}(\mathrm{IoT})+D_{1,2,3}(\mathrm{IoT}) \cdot \sum_{k=1}^{3} N_{k}(\mathrm{IoT}) \\
V_{\text {tot }}(\mathrm{IoT})[1]=D_{0}(\mathrm{IoT}) \cdot \mathrm{FC}_{0}(\mathrm{IoT}) \cdot N_{0}(\mathrm{IoT})+D_{1,2,3}(\mathrm{IoT}) \cdot \mathrm{FC}_{1,2,3}(\mathrm{IoT}) \cdot \sum_{k=1}^{3} N_{k}(\mathrm{IoT})
\end{gathered}
$$

\section{Tire and Tread Production}

\section{Material Composition}

According to the truck manufacturer, a typical heavy-duty truck tire weighs $63 \mathrm{~kg}$. Based on specifications for tire material composition used by the truck manufacturer, we assume a typical material composition for the tires according to Table 7 in the Appendix. The material composition of treads added in the retreading step is assumed to be the same as for the rubber part of a tire, see Table 8 in the Appendix. The weight of the tread is estimated to $10.7 \mathrm{~kg}$, based on communication with the retreading company.

\section{Manufacturing}

The tire manufacturing process is modeled using data from the production of passenger car tires ([33], [pp. 1752]). The data as given in [33] is presented in Table 9 in the Appendix, and the data used to describe tire and tread production is presented in Table 10 and Table 11, respectively. Process waste from tread and tire production is assumed to be handled as follows: rubber waste is incinerated, steel waste is sold as scrap steel, and tire waste is processed 
according to the EoL options described in Data Collection and Modeling of the Tire's End of Life in the Appendix.

\section{Use}

\section{Driving Distance Before Tire Exchange}

According to the representatives from the truck manufacturing company, a long-haul truck tire can be driven for about $2.5 \cdot 10^{5} \mathrm{~km}$ but is typically exchanged when there is still approximately $20 \%$ of mileage left. We thus assume that new tires are exchanged after $2 \cdot 10^{5} \mathrm{~km}\left(D_{0}\right.$ in Eq. 2). The representatives from the truck manufacturing company also indicated that the maximum distance that a retreaded tire can cover is about $80 \%$ compared to a new tire. The retreading company, on the other hand, claims that the quality of the retreaded tire is the same as new, as long as the process is done properly. External data sources also provide different numbers for the possible difference between the distance that a new and a retreaded tire can cover before it has to be exchanged. For example, Michelin claim on their website that their retreaded tires can cover $90 \%$ of the distance specified for new tires [34]. In a previously published LCA study, the authors state that the maximum distance for retreaded tires is in the range of $75 \%$ to $100 \%$ compared to new ones [35]. In this study, we use the truck manufacturer's estimation that retreaded tires are exchanged after $80 \%$ of the distance compared to new tires, i.e., after $1.6 \cdot 10^{5} \mathrm{~km}\left(D_{1,2,3}\right.$ in Eq. 2$)$. In the sensitivity analysis, we test values for $D_{1,2,3}$ (in the current state) between $1.5 \cdot 10^{5} \mathrm{~km}$ and $2.0 \cdot 10^{5} \mathrm{~km}$, i.e., between $75 \%$ and $100 \%$ of $D_{0}$.

As explained in Methodology, the distances $D_{0}$ and $D_{1,2,3}$ also depend on whether IoT is used or not. This can be explained by two different effects. Firstly, based on discussions with the truck manufacturer, we found that tire replacement is based on time-in-use rather than the actual condition. By using IoT to monitor the actual condition of the tire, it might thus be possible to only replace the tires when it is really needed, i.e., when the condition is measured as unsatisfactory. As stated above, tires currently have approximately $20 \%$ of distance left in them when exchanged. However, based on discussions with the retreading company, it is not obvious that the truck drivers would delay tire exchange even if they had data about the tire condition, since the timing of the tire exchange also correlates with the change of season. We thus estimate this effect of IoT on $D_{0}$ and $D_{1,2,3}$ to be in the range of $0 \%$ to $20 \%$. Secondly, IoT-enabled pressure monitoring could reduce unnecessary wear since the tire would always be used at optimal pressure. Based on discussions with the truck manufacturer, the distance that a tire can cover before it has to be replaced is reduced by $25 \%$ if driven at $80 \%$ of optimal tire pressure. We thus estimate this effect of IoT on $D_{0}$ and $D_{1,2,3}$ to be in the range between 0 and $25 \%$.

Combining the two effects presented above, we assume that $D_{0}$ and $D_{1,2,3}$ are all increased by $25 \%$ if IoT is used. In our sensitivity analysis, we test values between $0 \%$ and $50 \%$.

\section{Abrasion During Use}

Based on Pehlken and Roy [36], abrasion results in a 15\% weight loss of the tire during use. We assume that the material lost through abrasion is tread material (i.e., not steel). Further, we assume that the abrasion percentage is the same for new and retreaded tires and that it is not dependent on whether IoT is used or not. 


\section{Fuel Consumption}

Based on discussions with the truck manufacturer, the average fuel consumption is $0.32 \mathrm{l} / \mathrm{km}$ for a 'tractor/semi-trailer' and $0.48 \mathrm{1} / \mathrm{km}$ for a 'truck with trailer'. The fuel consumption depends on the tire pressure, which should be checked and corrected regularly. According to Brigdestone [37], the fuel consumption of a truck increases close to linearly in the time interval between zero and 48 weeks, if the tire pressure is not checked and adjusted. The fuel consumption, $\mathrm{FC}(t)$, can thus be described according to Equation 4, where $A$ is a constant and $\mathrm{FC}_{\mathrm{min}}$ is the minimal fuel consumption corresponding to optimal tire pressure. Brigdestone [37] further reports that the fuel consumption typically increases by $14 \%$ if the tire pressure is not checked for 48 weeks. Based on this, we can formulate Eq. 5, and derive the relationship between $\mathrm{FC}_{\min }$ and $A$ according to Eq. 6 .

$$
\begin{gathered}
\mathrm{FC}(t)=\mathrm{FC}_{\min }+A \cdot t \\
\mathrm{FC}(t=48)=\mathrm{FC}_{\min } \cdot 1.14 \\
A=\mathrm{FC}_{\text {min }} \cdot 0.0029
\end{gathered}
$$

Based on discussions with the truck manufacturer, we estimate the time between tire pressure checks, $\Delta t$, to be eight weeks in the current state. For a tractor/semi-trailer, we thus get $\mathrm{FC}(\Delta t /$ $2)=0.32 \mathrm{l} / \mathrm{km}$, and can calculate $\mathrm{FC}_{\text {min }}$ according to Eq. 7. This is the value of the fuel consumption when driving at optimal tire pressure.

$$
\mathrm{FC}_{\min }=\mathrm{FC}\left(\frac{\Delta t}{2}\right)-A \cdot \frac{\Delta t}{2}=\frac{0.32[1 / \mathrm{km}]}{1+0.0029[1 / \text { week }] \cdot 4[\text { weeks }]}=0.31631 / \mathrm{km}
$$

To get the fuel consumption per tire (Eq. 8 for a new tire and Eq. 9 for a retreaded tire), we introduce a 'rolling resistance fraction' which defines the share of the truck's fuel consumption that can be allocated to the tires (as opposed to other parts of the truck). This is based on Gutowski et al. [38], who reported a range for the rolling resistance fraction between $13 \%$ and $47 \%$ and used an average of $24 \%$. We follow their example and use $24 \%$ in our calculations, but test values between $13 \%$ and $47 \%$ in our sensitivity analysis.

Eqs. 8 and 9 also include a term to describe the abovementioned increase in fuel consumption caused by suboptimal tire pressure $\left(\Delta \mathrm{FC}_{\text {pressure }}\right)$. This term depends on how often the tire pressure is currently checked $(\Delta t)$. Note that in the IoT scenario, we assume optimal tire pressure, i.e., that $\Delta \mathrm{FC}_{\text {pressure }}=0$

In Eq. 9 (for retreaded tires), we also add a term to account for a possible increase in fuel consumption due to higher rolling resistance for retreaded tires compared to new ones $\left(\triangle \mathrm{FC}_{\text {retreading }}\right)$. This risk for higher rolling resistance for retreaded tires has been highlighted by e.g., Boustani et al. [35] and Gutowski et al. [38]. Tire manufacturer Continental has reported an increase in rolling resistance between 3 and 10\% [39]. However, that report was published 20 years ago, so it might be outdated. 
The value for the rolling resistance of retreaded tires is uncertain, especially as it depends on the quality achieved in the retreading process [35], which can vary between different retreading companies and tire types. According to the retreading company, the rolling resistance of the tires that they retread is the same as for new tires. Previous LCAs (e.g., [38]) have also estimated that the rolling resistance is the same for new and retreaded tires (i.e., $\Delta \mathrm{FC}_{\text {retreading }}=$ 0 ). In our LCA, we set $\Delta \mathrm{FC}_{\text {retreading }}=0$ as the base case assumptions. In our sensitivity analysis, we test values for $\Delta \mathrm{FC}_{\text {retreading }}$ between $0 \%$ and $10 \%$ of $\mathrm{FC}_{\text {min }}$. This range is based on the fuel efficiency grades defined by EU regulations, labeling truck tires from grade A to E [40]. According to Volvo Trucks [41], each increase in grade corresponds to an increase in fuel consumption by 2.5 percentage points. Using E-grade tires would thus cause a $10 \%$ increase in fuel consumption compared to using A-grade tires.

Note that the $\Delta \mathrm{FC}_{\text {pressure }}$ and $\Delta \mathrm{FC}_{\text {retreading }}$ are fully allocated to the tires, i.e., these terms are not multiplied with the rolling resistance fraction. The reason for this is that this additional fuel consumption is seen as directly caused by the tires.

$$
\begin{gathered}
\mathrm{FC}_{0}=\frac{\left(\mathrm{FC}_{\min } \cdot \text { rolling resistance fraction }\right)+\Delta \mathrm{FC}_{\text {pressure }}(\Delta t)}{\text { number of tires on truck }} \\
\mathrm{FC}_{1,2,3}=\frac{\left(\mathrm{FC}_{\min } \cdot \text { rolling resistance fraction }\right)+\Delta \mathrm{FC}_{\text {pressure }}(\Delta t)+\Delta \mathrm{FC}_{\text {retreading }}}{\text { number of tires on truck }}
\end{gathered}
$$

\section{Fuel Type}

Based on discussions with the truck manufacturer, MK1 diesel is often used as fuel for trucks in Sweden. On the Swedish market, biofuels are added to the MK1 giving a mix of fossil diesel (77 vol.\%), Hydrotreated Vegetable Oil (HVO) (17 vol\%), and Fatty Acid Methyl Esters (FAME) (5.5 vol\%) [42]. MK1 diesel has a density of $0.815 \mathrm{~kg} / \mathrm{l}$ and a heat value of $35.8 \mathrm{MJ} / 1$ [43]. The Ecoinvent entries that we use to describe the fuel mix are presented in Table 12 in the Appendix. Since no specific Ecoinvent entries were available for FAME or HVO, these were both modeled as 'Vegetable oil, refined'. Emissions to air from burning MK1 diesel in the truck are based on Hallberg et al. [43], using Euro6 values when data is available, and otherwise Euro5. The emissions are specified in Table 13 in the Appendix.

\section{Retreading}

Based on input from the retreading company, we here describe the retreading process and how it might be optimized if IoT were to be used. As explained in Methodology and depicted in Fig. 1, there are four decision points where tires are scrapped and we use the notation $X_{1}, X_{2}$, $X_{3}$, and $X_{4}$ to describe the share of tires passing through each decision point.

When a tire is due for exchange, the tire is demounted at a truck service point. A quick visual inspection is performed at the service workshop to evaluate the tire's condition. If the tire is deemed to be in satisfactory condition, it is sent for retreading. If not, the tire is sent to EoL management (described in Data Collection and Modeling of the Tire's End of Life in the Appendix). 
The retreading process starts with an inspection step, in which tires of unsatisfactory condition are scrapped. Thereafter, the tire enters the 'buffing' step, in which the old tread is removed. Then, a second inspection is done, whereby a small number of tires are scrapped. Subsequently, the tire is sprayed with cement to fill holes and a new tread is applied. After tread application, the tire is left in a vacuum chamber for some time and is then vulcanized. Finally, the tire is painted and inspected again. A small share of tires is scrapped at this point due to insufficient quality.

The shares $X_{1}, X_{2}, X_{3}$, and $X_{4}$ in the current state were estimated based on discussions with the retreading company and are listed in Table 1 . The effect of IoT on $X_{1}, X_{2}, X_{3}$, and $X_{4}$ was estimated as follows. We assume that IoT brings a more accurate assessment of retreadability, and thus that scrapping decisions are done as early as possible. As such, in the optimal case, no tires are discarded after the first decision point $\left(X_{2}=X_{3}=\right.$ $\left.X_{4}=1\right)$. We then estimate $X_{1}$ in the IoT scenario according to the following logic: given an accurate assessment of retreadability, we can assume that no tires which could have been retreaded are wrongly sorted as 'not retreadable' and no tires which are not suitable or retreading are wrongly sorted as 'retreadable'. Tires that are currently wrongly scrapped $\left(N_{\text {ws }}\right)$ are instead accepted at decision point 1 , and tires that are currently wrongly accepted $\left(N_{\text {wa }}\right)$ are scrapped at decision point 1 (rather than later). We estimate $N_{\text {wa }}$ as those tires which are currently scrapped at decision points 3 and 4 . We further assume that the current error rate for wrongly scrapping a tire is the same as the current error rate for wrongly accepting a tire $\left(N_{\mathrm{ws}}=N_{\mathrm{wa}}\right)$. In total this gives

$$
\begin{gathered}
N \cdot X_{1, \mathrm{IoT}}=N \cdot X_{1, \text { current }} \cdot X_{2, \text { current }}+N_{\mathrm{ws}}-N_{\text {wa }} \\
N_{\mathrm{wa}}=N_{\mathrm{ws}} \rightarrow X_{1, \mathrm{IoT}}=X_{1, \text { current }} \cdot X_{2, \text { current }}
\end{gathered}
$$

where $N$ is the total number of incoming tires to the retreading process. Based on this, we get the shares $X_{1}, X_{2}, X_{3}$, and $X_{4}$ in the IoT scenario as presented in Table 1 . In our sensitivity analysis, we test values for $X_{1, \mathrm{IOT}}$ between 0.7 and 1 , while keeping the other values constant.

Retreading process data, such as water and energy use, amount of incoming material, and emissions from the retreading process, was provided by the retreading company and is presented in Table 14 in the Appendix. Tire shreds that are scraped off the used tire before a new tread is applied are assumed to be sent to incineration (district heating generation).

Table 1 Shares of tires accepted for retreading at the four decision points, in the current state, and the IoT scenario.

\begin{tabular}{lllll}
\hline & $X_{1}$ (service point) & $X_{2}$ (first inspection) & $X_{3}$ (buffing) & $X_{4}$ (final inspection) \\
\hline Current state & 1 & 0,7 & 0,95 & 0,95 \\
IoT scenario & 0,7 & 1 & 1 & 1 \\
\hline
\end{tabular}




\section{Transports}

See Table 15 in the Appendix for all assumptions about transportation distances and modes of transport. For the transports where no direct reference was available, the following assumptions were made:

- Transport of raw material to tire/tread production is assumed to be within the country or close region where tire production takes place, with an estimated distance of $500 \mathrm{~km}$.

- The transportation distance for tires from a producer in Europe to a user in Sweden is assumed to be $1500 \mathrm{~km}$.

- The transportation distance for materials produced in Europe and used in the retreading plant in Sweden is assumed to be $1500 \mathrm{~km}$.

- The transportation distance between the service workshop and the retreading facility (both in Sweden) is assumed to be $150 \mathrm{~km}$.

- IoT components are assumed to be produced in China and shipped to Sweden, with an estimated distance of $20,000 \mathrm{~km}$.

\section{Added Impacts from loT}

To calculate the added impacts from the life cycle of the IoT solution itself, we include hardware production, energy use for data collection, transfer, storage, and processing in the cloud, as well EoL management of the hardware.

In order to support the IoT-enabled improvements included (reduced fuel consumption, delayed tire exchange, and increased retreading), we model the IoT hardware to include the following sub-units: (1) a Tire Pressure Monitoring System (TPMS) which allows for monitoring the tire pressure and transferring the data to the cloud, (2) a piezoelectric sensor system which allows for monitoring of sudden impacts on the tires (for example, from an uneven pavement) and transferring the data to the cloud, and (3) RFID tags which allow for unique identification of each cord (the main body of the tire) and each tread. Each sub-unit is described in more detail below, as are our estimations of energy requirements in the sensor units, the gateways, and the cloud. In the sensitivity analysis, we test values for the combined weight of all electronic components between $50 \%$ of the base value to $300 \%$ of the base value $(+200 \%)$. The large span is chosen because of the lack of specific Ecoinvent data for the electronic components. All hardware components are assumed to be treated as electronic scrap at EoL.

\section{TPMS}

The TPMS includes a sensor unit, a gateway, and a cable to supply the gateway with power [29]. The sensor unit is attached to the tire using a magnet, making it easy to mount and dismount. The lifetime of the TPMS sensor unit is assumed to be limited by the lifetime of its 
battery. The battery lifetime is noted as 5 years in the datasheet from a TPMS manufacturer [29]. Based on this, we assume that the TPMS can be reused throughout all three retreading steps. Assumptions about the material composition of the TPMS is based on the same datasheet [29] and on direct communication with the TPMS manufacturer. The hardware composition as well as the Ecoinvent entries used to describe each component is detailed in Table 16 in the Appendix.

\section{Piezoelectric Sensor System}

The piezoelectric sensor system includes a sensor unit, a gateway, and a cable to supply the gateway with power. The sensor unit is assumed to be passive, which means that it does contain a battery. As batteries are often the limiting component for the lifetime of sensor units, we assume that the sensor unit can be reused throughout all three retreading steps. Assumptions about the material composition of the piezoelectric sensor system are based on the system presented and tested in Mellquist et al. [23]. The hardware composition as well as the Ecoinvent entries used to describe each component is detailed in Table 17 in the Appendix.

\section{RFID Tags}

RFID tags are made up of an RFID chip and an RFID antenna [44]. Here, we also assume that the RFID tag has a plastic casing. Assumptions about the material composition of the RFID tag are based on Kanth et al. [8] as presented in Table 18 in the Appendix.

\section{Energy Requirements for Data Collection, Transmission, Storage, and Analysis}

We estimate the energy needed for data transfer, storage, and processing in the same way for both the TPMS and the piezoelectric sensor system, see Table 19 in the Appendix. We use data from (1) the power consumption of the TPMS stated in the technical data sheet from a TPMS manufacturer [29], (2) literature about the energy requirements of mobile data transfer [45], and (3) literature about the energy requirements of cloud computing [14]. To calculate the total time during which the sensors are used, we assume an average speed of the truck throughout its use of $70 \mathrm{~km} / \mathrm{h}$. In order to calculate the speed of data transfer, we assume that each transfer contains 4 bytes (32 bits) of information, which is the equivalent to a so-called float number, i.e., a floating-point number which is accurate up to approximately seven decimals [46]. Based on the datasheet from the TPMS manufacturer, the TPMS system transfers data from the tire once every 2 minutes, leading to a data transfer rate of 16 bits per minute, i.e., 0.267 bits per second.

To calculate the energy requirements for cloud computing, we assume that the data from the sensors is processed according to the 'storage-as-a-service' model as defined by Baliga et al. [14]. This means that the data is stored on the cloud and can be downloaded by a user for viewing or processing. No computing-intense tasks take place in the cloud. As the system modeled here is mainly meant to monitor the pressure and the impacts on the tire, this 'storage-as-a-service' type was deemed an appropriate estimation. Using this assumption, the energy requirements can, according to Baliga et al. [14], be calculated using Eq. A.1 in the Appendix. 


\section{Results}

\section{Difference in Impact Between Current State and IoT Scenario}

Using the ReCIPe single score, the environmental impact associated with the reference distance, $D_{\text {tot }}\left(2 \cdot 10^{6}\right.$ tire-kilometers), in the current state and the IoT scenario is shown in Fig. 2. The impact is presented per life cycle phase and with IoT-specific impacts shown separately. Credits for avoided impacts in EoL management of tires are also shown separately.

The total weighted life cycle impact is $6.64 \cdot 10^{-2} \mathrm{kPt}$ lower in the IoT scenario than in the current state, corresponding to a net impact reduction of approximately $4 \%$. This is thus the net effect of, on the one hand, impact reduction effects brought about by adding IoT $\left(-8.37 \cdot 10^{-2}\right.$ $\mathrm{kPt}$ combined) and, on the other hand, added impact from IoT hardware production, IoT energy use, IoT EoL management, and reduced credits from tire EoL management $(+1.73$. $10^{-2} \mathrm{kPt}$ combined).

The impact reduction stems from (1) lower fuel consumption $\left(-6.53 \cdot 10^{-2} \mathrm{kPt}\right),(2)$ a reduced need for new tires and thereby less impact from tire manufacturing $\left(-1.37 \cdot 10^{-2} \mathrm{kPt}\right),(3) \mathrm{a}$ reduced need for EoL management of tires and thereby less direct impact from EoL management $\left(-2.70 \cdot 10^{-3} \mathrm{kPt}\right)$, and $(4)$ a reduced need for retreading $\left(-2.00 \cdot 10^{-3} \mathrm{kPt}\right)$. The fact that there is a reduced need for retreading might seem counter-intuitive since the share of tires that are accepted for retreading is higher in the IoT scenario. The reason is that, since IoT increases the distance that each tire can cover before it has to be exchanged, the total amount of tires that are needed to cover the reference distance is lower, also resulting in a lower absolute number of tires being retreaded. The number of new and retreaded tires that are needed to cover the reference distance is shown in Table 2.

Impact current state vs IoT scenario, ReCIPe 2016 weighted single score

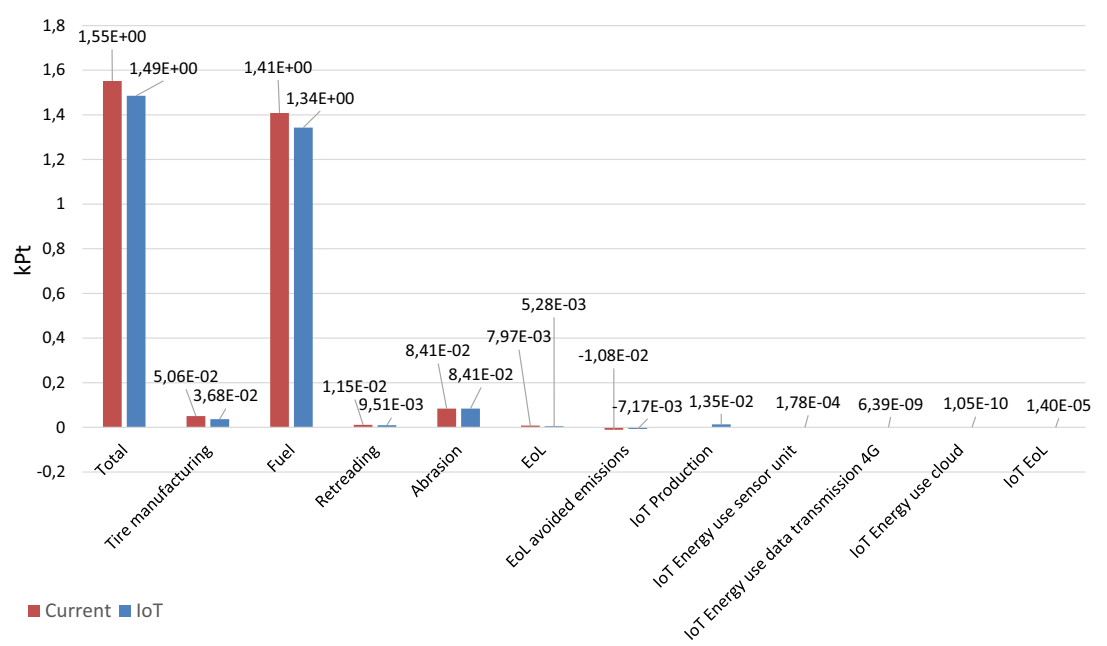

Fig. 2: Weighted impact, total and per life cycle phase, for the current state and the IoT scenario. Note that impacts related to the life cycle of the IoT hardware (production, energy use, EoL) are presented separately and are only applicable for the IoT scenario. 
Table 2 Number of tires that are needed to cover the reference distance, $2 \cdot 10^{6}$ tire-kilometers $\left(D_{\text {tot }}\right)$.

\begin{tabular}{lll}
\hline & \multicolumn{2}{l}{ Number of tires } \\
\cline { 2 - 3 } & Current state & IoT scenario \\
\hline New tires & 4.9 & 3.6 \\
One time retreaded tires & 3.1 & 2.5 \\
Two times retreaded tires & 2.0 & 1.8 \\
Three times retreaded tires & 1.2 & 1.2 \\
Total number of tires & 11.2 & 9.1 \\
\hline
\end{tabular}

The added impact in the IoT scenario is mainly a result of IoT hardware production $\left(+1.35 \cdot 10^{-2} \mathrm{kPt}\right)$ followed by a reduction of EoL credits assigned to the tires for avoided impacts in tire recycling and incineration $\left(+3.61 \cdot 10^{-3} \mathrm{kPt}\right)$. The energy requirements and EoL management of the IoT system do not add any significant impact $\left(+0.19 \cdot 10^{-3} \mathrm{kPt}\right.$, combined).

If the weighted impact in the two scenarios is compared per life cycle phase, the impact from tire manufacturing is reduced by $27 \%$, the impact from fuel consumption is reduced by $5 \%$, the impact from retreading is reduced by $17 \%$, and both the direct and the avoided impacts from EoL management are reduced by $34 \%$.

So far, we have only presented weighted impact results. Fig. 3 adds additional detail by presenting the impact difference between the current state and the IoT scenario for each impact category in the ReCIPe 2016 method. We see that for most impact categories, the impact is lower in the IoT scenario. However, in the following four categories, the IoT scenario has a significantly larger impact: freshwater eutrophication, freshwater ecotoxicity, marine ecotoxicity, and human non-carcinogenic toxicity. The added impact in these categories mainly stems from the production of the IoT hardware.

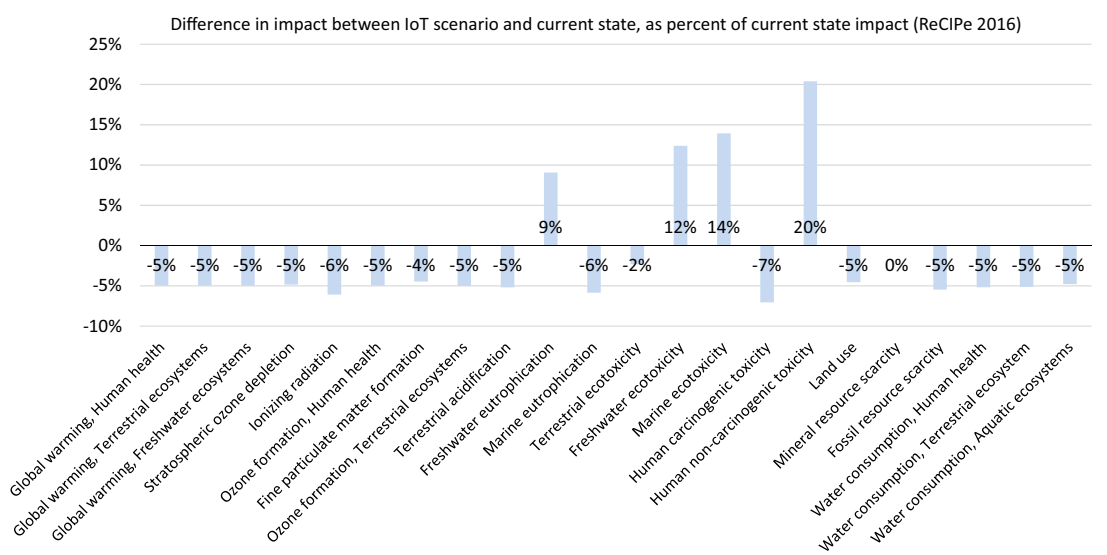

Fig. 3: Difference in impact between IoT scenario and current state (as percent of current state impact) for all impact categories in the ReCIPe 2016 method. 


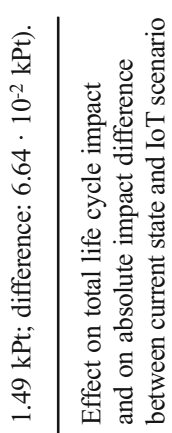

(3)

.

శั

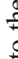

(2)

.

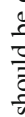

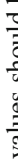$$
\text { 范 }
$$$$
\text { (n) }
$$

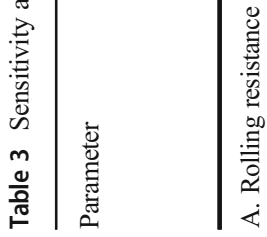

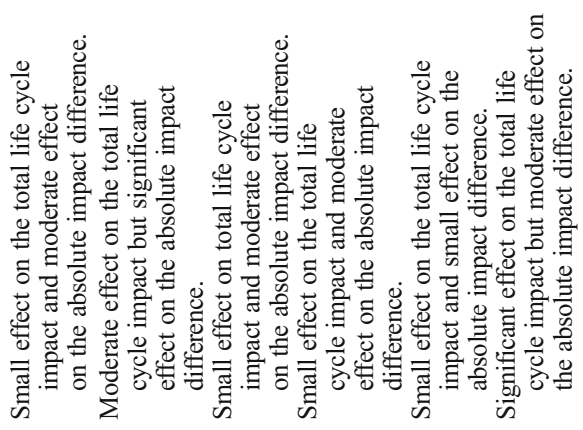

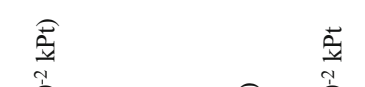

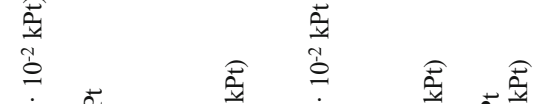

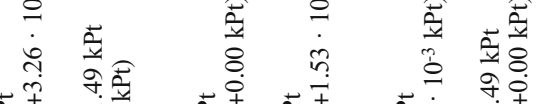

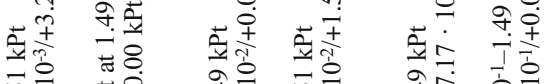

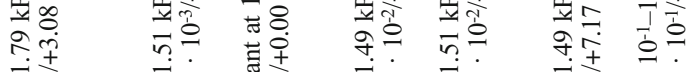

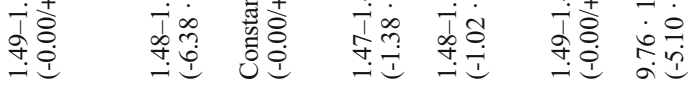

产

(

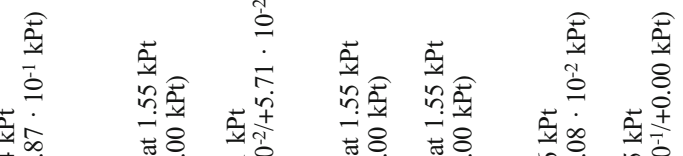

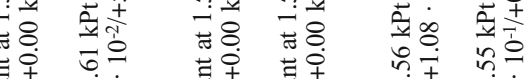

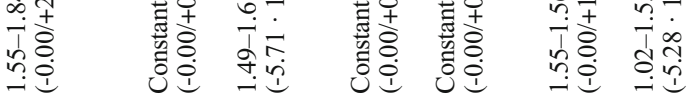

=

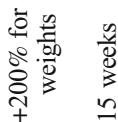

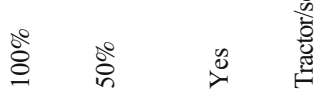

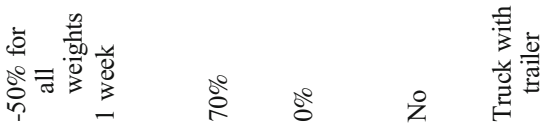

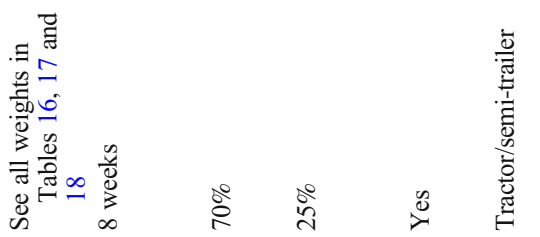

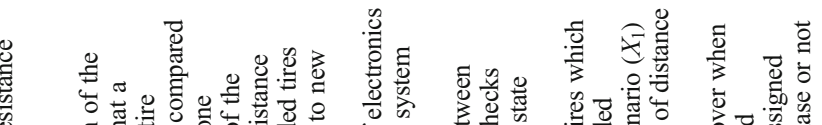

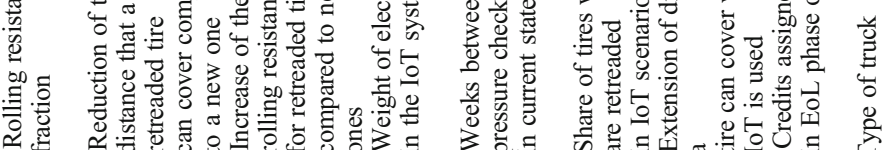

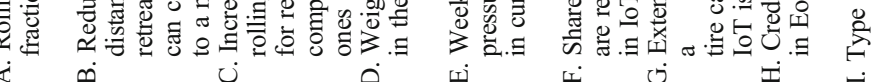




\section{Sensitivity Analysis}

We test the sensitivity of the results by varying the values of nine key parameters. Table 3 presents how the total life cycle impact changes when varying one parameter at a time. Fig. 4 shows the ranges within which the relative impact difference between the current state and the IoT scenario, calculated in relation to the total current state impact, varies per parameter.

Parameter $A$ (the rolling resistance fraction) and parameter $I$ (the type of truck) have the largest effect on the total life cycle impact. Parameter $A$ affects the current state and the IoT scenario equally, i.e., varying this assumption does not change the absolute difference in impact. However, it has a significant effect on the relative impact difference, as seen in Fig. 4. Parameter $I$ affects the total life cycle impact significantly but has a small effect on the relative difference.

Parameter $E$ (weeks between pressure checks in the current state) has a moderate effect on the total life cycle impact, but a large effect on the relative impact difference. Parameters $D$ (the weight of the IoT components), $F$ (the share of tires that are retreaded in the IoT scenario), and $G$ (the increase in distance that can be achieved through adding IoT) show small effects on the

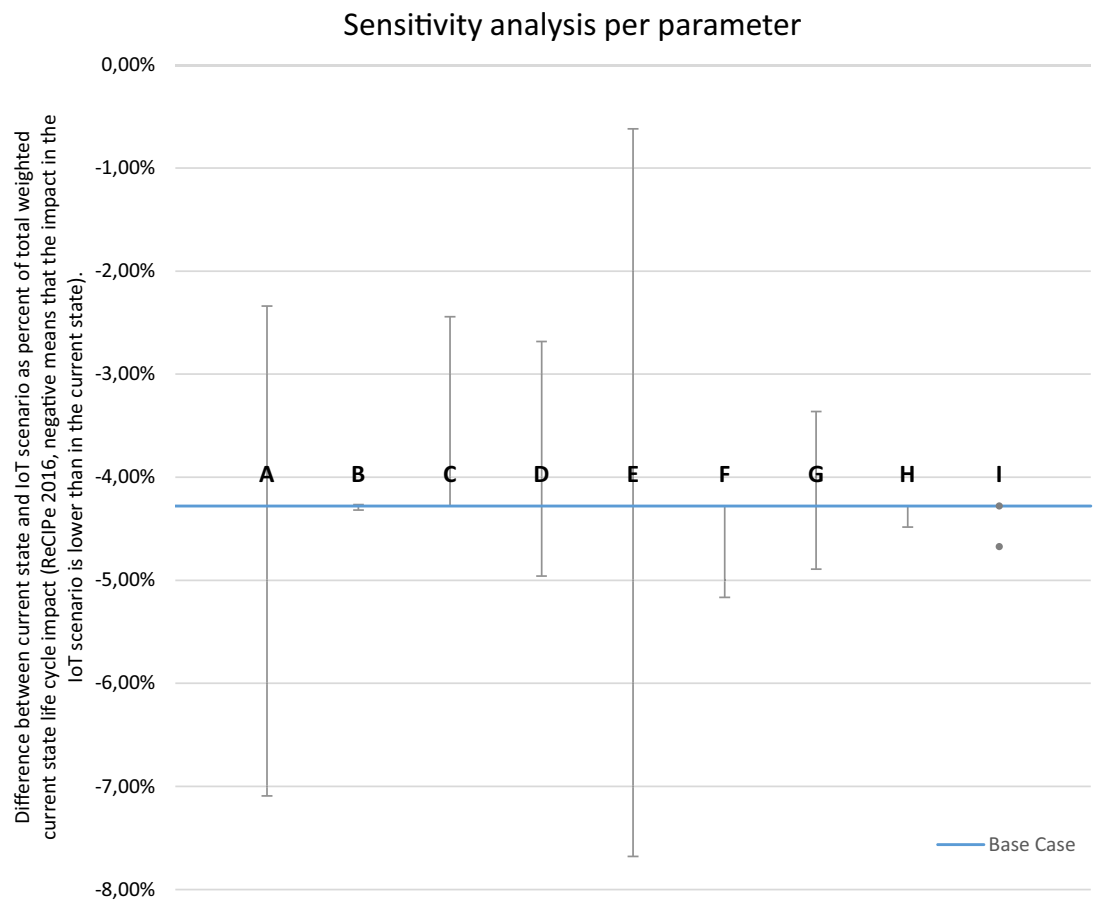

Fig. 4: How the relative difference in impact (as percent of current state impact) between the current state and the IoT scenario varies per parameter. Parameters $A$ to $I$ and their respective value ranges are explained in Table 3 . 
Sensitivity analysis: Extreme cases

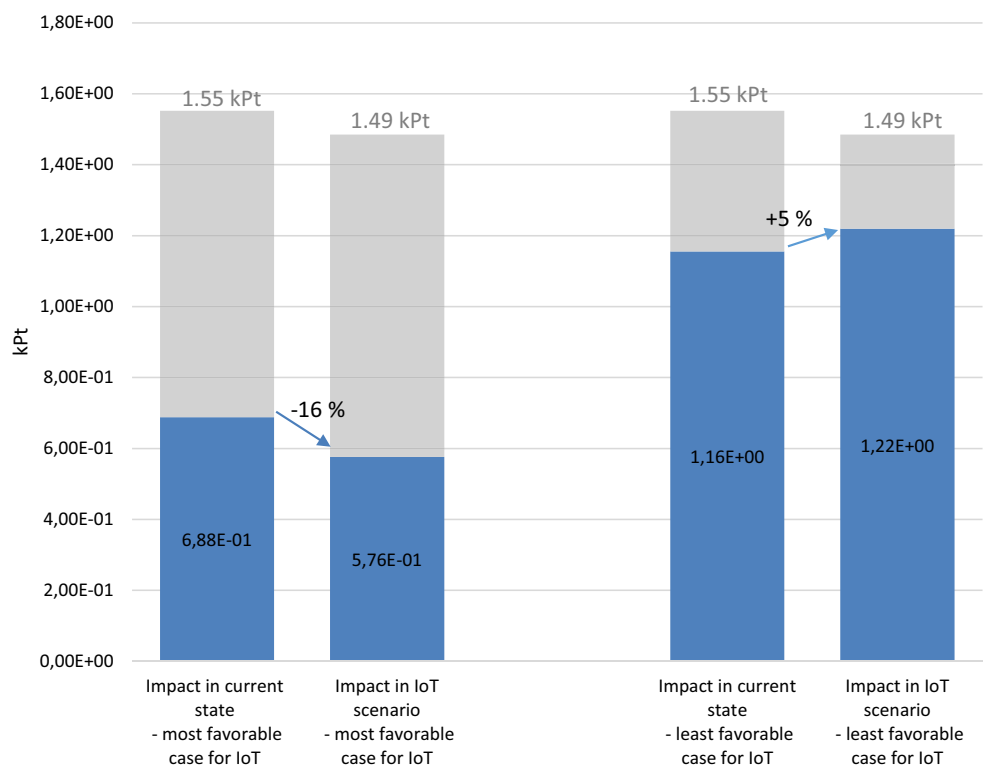

Fig. 5: Combining the nine parameter values to maximize the relative difference (in percent of current state impact) between the current state and the IoT scenario results in a maximum impact reduction of $16 \%$ and a maximum impact increase of $5 \%$.

total impact, but moderate effects on the relative difference. Parameter $C$ (the increase in rolling resistance for a retreaded tire compared to a new one) has a moderate effect on both the total impact and the relative difference. Parameters $B$ (the reduction in distance that a retreaded tire can cover compared to a new one) and $H$ (whether EoL credits are assigned or not) have small effects on both the total impact and the relative difference.

To get a total range of possible values for the relative impact difference between the current state and the IoT scenario, we construct two extreme cases: the 'most favorable case for IoT' and the 'least favorable case for IoT'. This is done by combining parameter values that maximize the relative impact difference (as percent of total current state impact) between the current state and the IoT scenario. Fig. 5 shows the impact in these two extreme cases. In the most favorable case for IoT, the IoT scenario leads to a $16 \%$ impact reduction compared to the current state. In the least favorable case, the IoT scenario performs $5 \%$ worse than the current state. Hence, while the base case presented in Difference in Impact Between Current State and IoT Scenario showed that adding IoT leads to a $4 \%$ net impact reduction, the sensitivity analysis shows that, in the most favorable case for IoT, the reduction could be significantly larger, while in the least favorable case, the IoT scenario could actually be worse than the current state. 


\section{Discussion}

Previous studies have investigated the potential for IoT to reduce environmental impacts in the use-phase of products (e.g., [20,21]). In this study, we add to this by showing that IoT can also bring significant impact reductions in the production phase since it can enable both product lifetime extension and increased product recovery. The results show that under base case assumptions, the IoT scenario brings a $4 \%$ net reduction of total weighted life cycle impact compared to the current state. Since the use-phase emissions dominate, a relatively small impact reduction in the use phase $(-5 \%)$ makes the largest contribution to the difference between the current state and the IoT scenario. The impact reduction in the tire production phase is significant $(-27 \%)$, but has a smaller effect on the total life cycle impact. It should be noted that these relative contributions between life cycle stages are specific for tires and would be different for products with a larger share of the impacts stemming from production.

In the case studied here, the largest added impact in the IoT scenario comes from the production of the IoT hardware. This could also be different for other types of products, especially if large amounts of data need to be transferred and processed, resulting in increased energy demand.

As seen in Results, when looking at each ReCIPe impact category separately (Fig. 3), the IoT scenario brings impact reductions for most impact categories. For four impact categories, however, the IoT scenario performs worse than the current state. This is an example of what Bonvoisin et al. [18] refer to as 'impact shifting,' i.e. that the impact in some categories is reduced while it increases in others. The added impacts in these categories are mainly stemming from the production of IoT hardware. It is thus important for designers to be aware of the fact that even in cases where using IoT brings net environmental reductions on a weighted basis, the IoT hardware itself comes with inherent environmental impacts, and efforts should be taken to minimize these.

Our sensitivity analysis showed that the results about the relative impact difference between the current state and the IoT scenario are sensitive to assumptions of three types: (1) assumptions about the use-phase emissions of tires, independent of whether IoT is used or not, (2) assumptions about the actual environmental impact reductions that IoT will bring about, and (3) assumptions about the hardware components used in the IoT solution.

The first type of assumptions includes parameters $A$ and $I$. Parameter $A$ describes the share of the total fuel consumption in the truck that should be allocated to the tires because of their rolling resistance. This parameter thus depends on which tires we expect are used. Changing this parameter does not change the absolute difference in impact between the current state and the IoT scenario, but it considerably affects the total life cycle impact of the tire, which is dominated by the use phase. If a low rolling resistance factor is assumed, the total life cycle impact becomes lower, and the relative difference between the current state and the IoT scenario becomes bigger. Parameter $I$ defines which type of truck is used. As stated previously, two options are considered: (1) a fully-loaded 'tractor/semi-trailer' or (2) a fully-loaded 'truck with trailer'. The use-phase impact per tire-kilometer is lower in (2) than in (1) and the relative impact difference between the current state and the IoT scenario is larger in (2) than in (1).

The fact that parameters $A$ and $I$ have a large influence on the total tire life cycle impact suggests that hauler companies should ensure that the tires and trucks that they use are appropriate for the type and amount of goods to be transported. The fuel efficiency that can be achieved in this way is likely to affect the impact per tire-kilometer more than adding IoT. However, based on the analysis done in this study, we cannot draw conclusions about which tires and trucks to use in which situation. 
The second type of assumptions includes parameters $E$ (how often the tire pressure is checked in the current state), $F$ (share of tires which are retreaded in IoT scenario), and $G$ (extension of distance a tire can cover when IoT is used). These parameters indicate to what extent IoT actually brings environmental impact reductions in the tire life cycle.

The difference in impact between the current state and the IoT scenario is especially sensitive to variations in parameter $E$. This shows that the results are not only dependent on the technological context, but also sensitive to modeling choices about the behavior of different actors. If drivers already have a routine in place to check the pressure quite often (every 1-2 weeks), then the addition of a pressure monitoring system will not bring any significant environmental benefit. Moreover, we cannot know for sure that the availability of up-to-date pressure data will actually lead to a behavioral change among the drivers to adjust the pressure more often.

Similarly, with regards to parameter $G$, even if the hauler company gets access to data about the condition of each tire, they might still exchange all tires at the same time, if that is more convenient or most cost-effective, for example. Further, to actually increase the share of tires that are retreaded (parameter $F$ ), the retreading company would need to be willing and able to act on the data supplied by the IoT solution, and adjust their sorting procedure accordingly. These findings echo the discussion in Dekoninck and Barbaccia [20] about the need to design for behavioral change so that the potential savings that IoT can bring are actually realized through user actions. When assessing IoT-enabled strategies, it is thus important to closely examine the context in which it is going to be implemented, including the current and expected behavior of actors along the product lifecycle.

In relation to the third type of assumptions, i.e., about the hardware components used to enable the IoT solution, the primary uncertainty lies in the choice of components and in the lack of reliable data about the impact of specific components. As the Ecoinvent database does not provide specific data for different types of sensors, nor for gateways, we used the Ecoinvent data entry 'unspecified electronic component' to describe these components. To deal with this uncertainty, we used a wide range of values for the weight of IoT components in our sensitivity analysis (parameter $D$ ). Varying parameter $D$ has a moderate but non-negligible effect on the weighted impact difference, and a large effect on the impact difference in the four impact categories: freshwater eutrophication, freshwater ecotoxicity, marine ecotoxicity, and human non-carcinogenic toxicity. This indicates that design decisions at this level can be important for the net environmental impact of IoT-enabled circular strategies. Based on this, as well as the fact that more and more products are being connected to the internet, we argue that more research is needed to produce detailed and reliable data of different electronic components used in connected products.

Another aspect related to the impact of the IoT hardware is the lifetime of the specific hardware components. In the case studied here, the lifetimes of the hardware components were sufficient to last through the multiple lifetimes of the core product (the tire). However, for other longer-lived product types, it is possible that the IoT components become obsolete while the rest of the product is still functioning. This aspect is important to keep in mind, since it could mean that adding IoT shortens the lifetime of the core product, instead of prolonging it.

Lastly, some limitations of this study should be mentioned. We have not included the possibility that IoT might enable additional retreading cycles, i.e., that tires could be retreaded four or five times instead of three. This was excluded since the stakeholders who were interviewed did not see an opportunity for this, mainly because of lacking demand from customers. Similarly, we did not investigate potential IoT-induced improvements (or deteriorations) in tire design, production, recycling, or incineration, since this was not mentioned by the stakeholders. Moreover, while this study focused on tires, IoT could be used more widely in trucks to support more fuel-efficient driving 
behavior, increased traceability, or optimized maintenance of other important components besides tires [47]. Such opportunities have not been investigated in this study.

Further, our results are based on the Swedish context, and might not be directly generalizable to other countries. Some context-specific aspects should thus be mentioned. Firstly, Sweden has a relatively high use of renewable fuels for transport compared to other countries (e.g., compared to the EU average [48]). Secondly, Sweden has cold winters, implying that Swedish hauler companies are cautious about extending the use time of tires into the winter season. Thirdly, Sweden has a welldeveloped collection and recycling system for used tires. Altogether, these context-specific aspects likely mean that the IoT-induced environmental impact reduction for tires is smaller in Sweden than in many other countries.

With regards to the methods used, we presented our LCA results both as a single impact score based on weighting and per impact category in the ReCIPe method. While weighting always adds subjectivity, it was meaningful to use weighting in this study as it supported a more direct comparison of total environmental impact of the two scenarios. However, it was also important to present the results per impact category as this allowed for a more nuanced discussion of the findings and showed that the IoT scenario actually performed worse for four impact categories. Finally, the focus of our assessment was entirely on environmental impact, and we did not try to quantify the potential safety and/or cost improvements that might come from adding IoT.

\section{Conclusions}

The aim of this paper was to assess the net environmental impact reduction of using IoT to support circular strategies in the life cycle of heavy-duty truck tires in Sweden. Doing so, we aimed to gain insights into when and how it makes environmental sense to embed IoT hardware, such as sensors and communication devices, into products to stimulate circular strategies. We compared the environmental impact from tires in the current state with an 'IoT scenario,' in which IoT brought about (1) reduced fuel consumption, (2) delayed tire exchange, and (3) increased retreading of tires. The biggest impact reduction in the IoT scenario was found to come from fuel consumption reduction as a result of IoT-enabled tire pressure monitoring. Using the ReCIPe 2016 method for impact assessment, we found that the weighted tire life cycle impact was $4 \%$ lower in the IoT scenario than in the current state. However, we also found that the IoT scenario performed significantly worse for four ReCIPe impact categories (freshwater eutrophication, freshwater ecotoxicity, marine ecotoxicity, and human non-carcinogenic toxicity). Through sensitivity analysis, we showed that the results are sensitive to the underlying modeling choices. We varied nine key parameters to find the range of possible values for the relative impact difference between the current state and the IoT scenario. In the most favorable case for IoT, the impact reduction was found to be $16 \%$. In the least favorable case for IoT, we found a $5 \%$ impact increase in the IoT scenario.

The results are sensitive to assumptions about the current and expected behavior of different actors along the life cycle. This indicates that, when exploring or proposing IoT-enabled circular strategies, it is important that designers thoroughly investigate the context in which the strategy is to be implemented and, when needed, design solutions that actually ensure behavioral change. We also found that design decisions at the level of specific IoT components can be important to the net environmental impact of IoT-enabled circular strategies.

Future research should perform similar assessments for other types of products. In addition, efforts should be put into gathering more detailed inventory data about the environmental impact of specific IoT components, such as sensors and gateways. 
Code Availability The SimaPro file is available upon request.

Author Contributions Emilia Ingemarsdotter: Conceptualization, methodology, formal analysis, investigation, writing - original draft

Derek Diener: Methodology, formal analysis, investigation, writing — review and editing

Simon Andersson: Formal analysis, investigation

C. Jonasson: Investigation, writing - review and editing

A-C. Mellquist: Investigation, writing-review and editing

Thomas Nyström: Funding acquisition, investigation

Ella Jamsin: Supervision, writing — review and editing

Ruud Balkenende: Supervision, funding acquisition, writing - review and editing

Funding Information This research was funded by the Circular European Economy Innovative Training Network, Circ€uit, an action funded by the European Commission under the Horizon 2020 Marie Skłodowska Curie Actions 2016 - Grant Agreement 721909 (authors E.I., E.J., and R.B), and by the Swedish Innovation Agency (Vinnova), under the Innovations for a Sustainable Society call—dnr 2016-03356 (authors D.D., S.A., C.J., A-C.M., and T.N.). We are grateful to the company representatives who provided input to the study and to the anonymous reviewers for valuable feedback.

Data Availability The data that was used is provided in the Appendix.

\section{Declarations}

Conflicts of Interest The authors have no conflicts of interest to declare that are relevant to the content of this article.

\section{Appendix}

\section{Data Collection and Modeling of the Tire's End of Life}

Tires that are deemed unsuitable for retreading are sent to EoL processing. Below, we first present how scrapped tires are divided between different EoL streams. Then, we present more details about the processes in each such EoL stream. As mentioned in Methodology, we use system expansion to account for impacts that can be avoided elsewhere when tires are recycled or incinerated. The 'credits' received by the tires because of these avoided impacts depend on assumptions made about the recycling and incineration processes. In the sensitivity analysis, we deal with this uncertainty by showing the total results both with and without credits from the EoL phase. 


\section{Distribution of Scrapped Tires into Different EoL Streams}

In January 2019, the biggest tire recycling company in Sweden estimated that, out of the tires that they receive, $60 \%$ is sent for energy recovery in incineration (either in cement production or in district heating generation), while $39 \%$ is sent for material recycling and $1 \%$ is exported [49]. Material recycling included three streams: production of rubber granulates for artificial turfs (12\%), cutting into blasting mats used on construction sites $(22 \%)$, and shredding into drainage material to be used in construction or landfills $(5 \%)$ [49].

In August 2019, the same recycling company announced that they will stop producing rubber granulates for artificial turfs [50]. Based on correspondence with the recycling company, we assume that this share instead goes to incineration. Thus, we estimate the current incineration percentage to be $72 \%$. Based on numbers from SDAB [49], we estimate that about half of this (36\% of total) goes to the cement industry. The other half (again, 36\% of the total) is expected to go to district heating generation.

The percentages of scrapped tires going in the different EoL streams, as used in our calculations, are presented in Table 4 . Here, we disregard the $1 \%$ of tires that are exported and instead add $0.25 \%$ to each waste stream to reach $100 \%$.

All EoL options require that the tires are cut or shredded. Skenhall et al. [52] reported that the shredding process can be powered by electricity $(20 \mathrm{kWh} /$ ton tire) or diesel fuel (108 MJ diesel/ton tire). We assume that electricity is used since this is the most common option.

Table 4 Share of scrapped tires going to each EoL option

\begin{tabular}{lr}
\hline End of life options & wt $\%$ \\
\hline Cement kiln incineration & $36.25 \%$ \\
District heating incineration & $36.25 \%$ \\
Blasting mats & $22.25 \%$ \\
Drainage material & $5.25 \%$ \\
\hline
\end{tabular}




\section{Energy Recovery in Cement Kiln Incineration}

Based on a previous LCA study [53], tire shreds that are incinerated in cement kilns replace fuel (coal and pet-coke) as well as iron ore, which is used as an additive in cement production. While the referenced study is 14 years old, coal is still used in cement production at the largest Swedish cement producing company [54].

Further, we follow the calculations by Hallberg et al. [53] who estimate that other emissions than $\mathrm{CO}_{2}$ from cement kiln incineration can be neglected (both when burning tire shreds, and when burning coal/pet-coke). The amount of replaced fuel per tire mass, and the emissions from incinerating tire shreds, are based on Hallberg et al. [53] and presented in Table 5.

Table 5 Data used to model incineration of tires in cement kiln

\begin{tabular}{|c|c|c|c|}
\hline & Amount & Reference & Modeled as \\
\hline Emissions to air: $\mathrm{CO}_{2}$, fossil & $\begin{array}{c}2.55 \mathrm{~kg} / \mathrm{kg}_{\text {tire, excluding }} \\
\text { natural rubber content }\end{array}$ & {$[53]$} & Carbon dioxide, fossil \\
\hline Emissions to air: $\mathrm{CO}_{2}$, biogenic & $\begin{array}{l}2.55 \mathrm{~kg} / \mathrm{kg}_{\text {natural rubber in }} \\
\text { tire }\end{array}$ & {$[53]$} & Carbon dioxide, biogenic \\
\hline Electricity use, tire shredding & $20 \mathrm{Wh} / \mathrm{kg}_{\text {tire }}$ & {$[52]$} & $\begin{array}{l}\text { Electricity, medium voltage } \\
\qquad\{\mathrm{SE}\} \mid \text { market for } \mid \text { cut-off, } \mathrm{S}\end{array}$ \\
\hline Replaced fuel: coal & $0.75 \mathrm{~kg}_{\text {coal }} / \mathrm{kg}_{\text {tire }}$ & {$[53]$} & $\begin{array}{l}\text { Hard coal \{Europe, without } \\
\text { Russia } \\
\text { and Turkey }\} \mid \text { market for } \\
\text { hard coal | cut-off, S }\end{array}$ \\
\hline Replaced fuel: pet-coke & $0.25 \mathrm{~kg}_{\text {coal }} / \mathrm{kg}_{\text {tire }}$ & {$[53]$} & $\begin{array}{r}\text { Petroleum coke }\{\mathrm{GLO}\} \mid \\
\text { market for } \mid \text { cut-off, } \mathrm{S}\end{array}$ \\
\hline Replaced material: iron ore & $0.16 \mathrm{~kg}_{\text {iron ore }} / \mathrm{kg}_{\text {tire }}$ & {$[53]$} & $\begin{array}{l}\text { Iron ore, beneficiated, } 65 \% \text { Fe } \\
\{\text { GLO }\} \mid \text { market for } \mid \text { cut-off, } \mathrm{S}\end{array}$ \\
\hline $\begin{array}{l}\text { Avoided emissions to air: } \mathrm{CO}_{2} \text { released } \\
\text { from burning coal }\end{array}$ & $2.888 \mathrm{~kg}_{\mathrm{CO} 2} / \mathrm{kg}_{\text {coal }}$ & {$[53]$} & Carbon dioxide, fossil \\
\hline $\begin{array}{l}\text { Avoided emissions to air: } \mathrm{CO}_{2} \text { released } \\
\text { from burning pet-coke }\end{array}$ & $3.0 \mathrm{~kg}_{\mathrm{CO} 2} / \mathrm{kg}_{\text {pet-coke }}$ & {$[53]$} & Carbon dioxide, fossil \\
\hline
\end{tabular}




\section{Energy Recovery in District Heating Incineration}

The tire shreds in this EoL stream replace fuel that would otherwise have been used to produce district heating. Based on Hallberg et al. [53], tire shreds that are incinerated for district heating replace coal or biomass from wood. That study estimates that in 2006, 57\% of the tires were incinerated in a bioburner replacing biomass, and $43 \%$ in a coal burner replacing coal. These numbers were based on the district heating plant 'Händelöverket,' which in 2011 reported that $95 \%$ of their fuel is either renewable or waste-based (e.g., tires), only using coal at peak demand [55]. Based on this, we instead assume that the tires replace $95 \%$ solid biomass and 5\% coal. The amount of replaced fuel per tire mass, and the emissions from incinerating tire shreds, are based on Hallberg et al. [53] and presented in Table 6.

Table 6 Data used to model incineration of tires in district heating production

\begin{tabular}{|c|c|c|c|}
\hline & Amount & Reference & Modeled as \\
\hline Electricity use, tire shredding & $20 \mathrm{Wh} / \mathrm{kg}_{\text {tire }}$ & {$[53]$} & $\begin{array}{l}\text { Electricity, medium voltage }\{\mathrm{SE}\} \mid \\
\quad \text { market for } \mid \text { cut-off, } \mathrm{S}\end{array}$ \\
\hline \multicolumn{4}{|l|}{ Tires incinerated in a coal burner } \\
\hline Emissions to air: $\mathrm{CO}$ & $0.738 \mathrm{~g} / \mathrm{kg}_{\text {tire }}$ & {$[53]$} & Carbon monoxide \\
\hline Emissions to air: $\mathrm{CO}_{2}$, fossil & $\begin{array}{l}2.55 \mathrm{~kg} / \mathrm{kg}_{\text {tire, excluding natural }} \\
\text { rubber content }\end{array}$ & [53] & Carbon dioxide, fossil \\
\hline Emissions to air: $\mathrm{CO}_{2}$, biogenic & $2.55 \mathrm{~kg} / \mathrm{kg}_{\text {natural rubber in tire }}$ & [53] & Carbon dioxide, biogenic \\
\hline Emissions to air: $\mathrm{N}_{2} \mathrm{O}$ & $0.54 \mathrm{~g} / \mathrm{kg}_{\text {tire }}$ & [53] & Dinitrogen monoxide \\
\hline Emissions to air: $\mathrm{NH}_{3}$ & $0.0364 \mathrm{~g} / \mathrm{kg}_{\text {tire }}$ & {$[53]$} & Ammonia \\
\hline Emissions to air: $\mathrm{NO}_{\mathrm{x}}$ & $2.83 \mathrm{~g} / \mathrm{kg}_{\text {tire }}$ & {$[53]$} & Nitrogen oxides \\
\hline Emissions to air: Particles & $0.041 \mathrm{~g} / \mathrm{kg}_{\text {tire }}$ & {$[53]$} & Particulates \\
\hline Emissions to air: $\mathrm{SO}_{2}$ & $10.7 \mathrm{~g} / \mathrm{kg}_{\text {tire }}$ & [53] & Sulfur dioxide \\
\hline $\begin{array}{l}\text { Replaced heat (otherwise generated } \\
\text { from burning coal) }\end{array}$ & $\begin{array}{l}4.333\left(\mathrm{kWh}_{\text {heat }} / \mathrm{kg}_{\text {coal }}\right) \cdot 1.17 \\
\quad\left(\mathrm{~kg}_{\text {coal }} / \mathrm{kg}_{\text {tire }}\right)\end{array}$ & [53] & $\begin{array}{l}\text { Heat, district or industrial, other than } \\
\text { natural gas }\{\text { RoW }\} \mid \text { heat production, at } \\
\text { coal coke industrial furnace } 1-10 \mathrm{MW} \\
\text { cut-off, S }\end{array}$ \\
\hline \multicolumn{4}{|l|}{ Tires incinerated in a bio boiler } \\
\hline Emissions to air: $\mathrm{CO}$ & $0.0764 \mathrm{~g} / \mathrm{kg}_{\text {tire }}$ & {$[53]$} & Carbon monoxide \\
\hline Emissions to air: $\mathrm{CO}_{2}$, fossil & $\begin{array}{l}2.55 / \mathrm{kg}_{\text {tire, excluding natural rubber }} \\
\text { content }\end{array}$ & [53] & Carbon dioxide, fossil \\
\hline Emissions to air: $\mathrm{CO}_{2}$, biogenic & $2.55 / \mathrm{kg}_{\text {natural rubber in tire }}$ & {$[53]$} & Carbon dioxide, biogenic \\
\hline Emissions to air: $\mathrm{N}_{2} \mathrm{O}$ & $0.33 \mathrm{~g} / \mathrm{kg}_{\text {tire }}$ & {$[53]$} & Dinitrogen monoxide \\
\hline Emissions to air: $\mathrm{NH}_{3}$ & $0.000765 \mathrm{~g} / \mathrm{kg}_{\text {tire }}$ & {$[53]$} & Ammonia \\
\hline Emissions to air: $\mathrm{NO}_{\mathrm{x}}$ & $2.6 \mathrm{~g} / \mathrm{kg}_{\text {tire }}$ & [53] & Nitrogen oxides \\
\hline Emissions to air: Particles & $0.0211 \mathrm{~g} / \mathrm{kg}_{\text {tire }}$ & {$[53]$} & Particulates \\
\hline Emissions to air: $\mathrm{SO}_{2}$ & $2.62 \mathrm{~g} / \mathrm{kg}_{\text {tire }}$ & {$[53]$} & Sulfur dioxide \\
\hline $\begin{array}{l}\text { Replaced heat (otherwise generated } \\
\text { from burning biomass) }\end{array}$ & $\begin{array}{c}1.519\left(\mathrm{kWh}_{\text {heat }} / \mathrm{kg}_{\text {biomass }}\right) \\
3.33\left(\mathrm{~kg}_{\text {biomass }} / \mathrm{kg}_{\text {tire }}\right)\end{array}$ & {$[51]$} & $\begin{array}{l}\text { Heat, district or industrial, other than } \\
\text { natural gas }\{\mathrm{SE}\} \mid \text { heat and power } \\
\text { co-generation, wood chips, } 6667 \mathrm{~kW} \text {, } \\
\text { state-of-the-art } 2014 \mid \text { cut-off, } \mathrm{S}\end{array}$ \\
\hline
\end{tabular}

Table 7 Raw materials in tires, based on interviews with representatives from the truck manufacturer.

\begin{tabular}{lll}
\hline Raw materials in tires & Assumed wt $\%$ & Weight (kg) \\
\hline Total tire & $100 \%$ & 63 \\
Natural rubber & $37 \%$ & 23.3 \\
Synthetic rubber & $9 \%$ & 5.7 \\
Carbon black & $24 \%$ & 15.1 \\
Organic chemicals & $8 \%$ & 5 \\
Steel & $22 \%$ & 13.9 \\
\hline
\end{tabular}


Table 8 Raw materials in treads, based on the assumption that treads have the same material composition as the rubber part of tires.

\begin{tabular}{lll}
\hline Raw materials in treads & Assumed wt $\%$ & Weight $(\mathrm{kg})$ \\
\hline Total tread & $100 \%$ & 10.7 \\
Natural rubber & $47 \%$ & 5.0 \\
Synthetic rubber & $12 \%$ & 1.3 \\
Carbon black & $31 \%$ & 3.3 \\
Organic chemicals & $10 \%$ & 1.1 \\
\hline
\end{tabular}

\section{Recycling as Drainage Material}

For this EoL stream, $1 \mathrm{~kg}$ of tire shreds is estimated to replace $2.5 \mathrm{~kg}$ crushed stone which would otherwise have been used as drainage material in landfills or construction [53].

\section{Recycling as Blasting Mats}

For this EoL stream, the tires are used as blasting mats in road and construction work. We did now find specific data about the impacts of blasting mats. As a rough approximation, we assume that cutting the tires and binding them into a blasting mat is similar to the electricity requirement for shredding tires. Blasting mats are generally made from old tires, thus no replacement credits are assigned to the tires for this secondary use. At the end of a blasting mat's life, it is assumed to be incinerated.

\section{Other Data Tables}

Based on the data given in Table 9, we derive process input and emission values for tires as presented in Table 10, and for treads as presented in Table 11. To model tire production, we use the

Table 9 Inputs, emissions, and wastes in tire production process as given in [33] per 1 passenger car tire à 9.497 $\mathrm{kg}$. The data is given per step in the tire production process: 'compound blending', 'rolling and extrusion', 'cutting and forming', 'vulcanizing and testing'. However, for emissions, the data is only given as a total (not per step). Moreover, a certain amount of electricity and water is reported for 'other three processes'. This refers to electricity and water used in the three processes 'rolling and extrusion', 'cutting and forming', and 'vulcanizing and testing' collectively, i.e., the available data does not indicate how much originate from which of the three processes.

\begin{tabular}{|c|c|c|c|c|c|c|}
\hline & $\begin{array}{l}\text { Compound } \\
\text { blending }\end{array}$ & $\begin{array}{l}\text { Rolling } \\
\text { and } \\
\text { extrusion }\end{array}$ & $\begin{array}{l}\text { Cutting } \\
\text { and } \\
\text { forming }\end{array}$ & $\begin{array}{l}\text { Vulcanizing } \\
\text { and testing }\end{array}$ & $\begin{array}{l}\text { 'Other } \\
\text { three } \\
\text { processes' }\end{array}$ & Total \\
\hline Electricity (MJ/tire) & 14.44 & 4.57 & 1.7 & 3.01 & 11.13 & 34.85 \\
\hline Water $(\mathrm{kg} /$ tire $)$ & 6.96 & 0 & 0 & 0 & 16.56 & 23.52 \\
\hline Steam $(\mathrm{kg} /$ tire $)$ & 0.76 & 0.2 & 0.39 & 15.89 & 0 & 17.24 \\
\hline Emissions to air: PM (g/tire) & - & - & - & - & - & 243.51 \\
\hline Emissions to air: VOCs (g/tire) & - & - & - & - & - & 0.005 \\
\hline Emissions to water: $\mathrm{COD}(\mathrm{g} / \mathrm{kg}$ tire $)$ & - & - & - & - & - & 1.73 \\
\hline $\begin{array}{l}\text { Emissions to water: } \\
\mathrm{NH} 4+-\mathrm{N} \text { (g/tire) }\end{array}$ & - & - & - & - & - & 0.19 \\
\hline $\begin{array}{l}\text { Emissions to water: suspended solid } \\
\text { (g/tire) }\end{array}$ & - & - & - & - & - & 0.69 \\
\hline Waste wire cord fabric (kg/tire) & 0 & 0.002 & 0.015 & 0.001 & 0 & 0.018 \\
\hline Waste fiber fabric (kg/tire) & 0 & 0.001 & 0.02 & 0.001 & 0 & 0.022 \\
\hline Waste cord thread (kg/tire) & 0 & 0.001 & 0 & 0 & 0 & 0.001 \\
\hline Waste rubber $(\mathrm{kg} /$ tire $)$ & 0.001 & 0.001 & 0 & 0 & 0 & 0.002 \\
\hline Waste steel wire (kg/tire) & 0 & 0.001 & 0.003 & 0 & 0 & 0.004 \\
\hline Waste tire (kg/tire) & 0 & 0 & 0 & 0.073 & 0 & 0.073 \\
\hline
\end{tabular}


Table 10 Data used to model tire production (per kg tire), based on [33].

\begin{tabular}{|c|c|c|}
\hline Input/output & Amount & Modeled as \\
\hline Input: electricity (MJ/kg_tire) & 3.67 & Electricity, medium voltage $\{\mathrm{SE}\} \mid$ market for $\mid$ cut-off, $\mathrm{S}$ \\
\hline Input: water ( $\mathrm{kg} / \mathrm{kg}$ tire $)$ & 2.48 & $\begin{array}{l}\text { Tap water }\{\text { Europe without Switzerland }\} \mid \text { market for } \mid \\
\text { cut-off, } S\end{array}$ \\
\hline Input: steam ( $\mathrm{kg} / \mathrm{kg}$ tire $)$ & 1.82 & Steam, in chemical industry $\{\mathrm{GLO}\} \mid$ market for $\mid$ cut-off, $\mathrm{S}$ \\
\hline Emissions to air: $\mathrm{PM}$ (g/kg tire) & 25.64 & Particulates, SPM \\
\hline Emissions to air: VOCs (g/kg tire) & 0.00053 & VOC, volatile organic compounds, unspecified origin \\
\hline Emissions to water: $\mathrm{COD}$ (g/kg tire) & 0.18 & COD, chemical oxygen demand \\
\hline Emissions to water: $\mathrm{NH} 4+-\mathrm{N}(\mathrm{g} / \mathrm{kg}$ tire $)$ & 0.02 & Ammonia \\
\hline $\begin{array}{l}\text { Emissions to water: suspended solid } \\
\text { (g/kg tire })\end{array}$ & 0.073 & Suspended solids, unspecified \\
\hline Waste: rubber ( $\mathrm{kg} / \mathrm{kg}$ tire $)$ & 0.0002 & $\begin{array}{l}\text { District heating incineration (described in Data collection } \\
\text { and Modeling of the Tire's End of Life) }\end{array}$ \\
\hline Waste: steel wire (kg/kg_tire) & 0.0004 & Scrap steel $\{\mathrm{GLO}\} \mid$ market for $\mid$ cut-off, $\mathrm{S}$ \\
\hline Waste: tires ( $\mathrm{kg} / \mathrm{kg}$ tire) & 0.0077 & $\begin{array}{l}\text { As described in Data collection and Modeling of the } \\
\text { Tire's End of Life }\end{array}$ \\
\hline
\end{tabular}

total values. To model tread production, we use the data for the first two steps given in [33], i.e., 'compound blending,' and 'rolling and extrusion'. When the data from [33] is only given as a total, we allocate one-fourth of these values to each of the four process steps. For the data reported in the column 'other three processes,' we allocate one-third of the values to each of the three steps ('rolling and extrusion,' 'cutting and forming,' and 'vulcanizing and testing'). Since the tread is assumed to not contain steel, no steel scrap is modeled in tread production. 'Fabric' and 'thread' waste is neglected for both tires and tread, as it is also not included in the assumed tire/tread composition.

$$
E_{\text {cloud }}=\frac{B_{d} \cdot D}{3600}\left(E_{T}+1.5 \frac{P_{\mathrm{st}, \mathrm{SR}}}{C_{\mathrm{st}, \mathrm{SR}}}\right)+2 B_{d} \frac{1.5 P_{\mathrm{SD}}}{B_{\mathrm{SD}}}[\mathrm{W}] \cdot \text { total hours of tire use }[\mathrm{h}]
$$

where

$B_{d} \quad$ is the number of bits transferred per second, estimated as $B_{d}=1 / 2^{*}$ [transfers $\left./ \mathrm{min}\right] \cdot 1 /$ $60[\mathrm{~min} / \mathrm{second}] \cdot 4^{* *}$ [bytes/transfer $] \cdot 8$ [bits/byte $]=0.267[\mathrm{bits} / \mathrm{s}]$.

$D \quad$ is number of downloads/uploads per hour, i.e. $30^{*}$ [transfers/hour].

$E_{T} \quad$ is the cloud-side energy needed to transfer of $1 \mathrm{bit}$, estimated to $2.7^{* * * *}[\mu \mathrm{J} / \mathrm{bit}]$.

Table 11 Data used to model tread production, based on [33].

\begin{tabular}{|c|c|c|}
\hline Input/output & Amount & Modeled as \\
\hline Input: electricity ( $\mathrm{MJ} / \mathrm{kg}$ _tread) & 2.392 & Electricity, medium voltage $\{\mathrm{SE}\} \mid$ market for $\mid$ cut-off, $\mathrm{S}$ \\
\hline Input: water $(\mathrm{kg} / \mathrm{kg}$ tread $)$ & 1.314 & Tap water $\{$ Europe without Switzerland $\} \mid$ market for $\mid$ cut-off, $S$ \\
\hline Input: steam (kg/kg_tread) & 0.101 & Steam, in chemical industry $\{\mathrm{GLO}\} \mid$ market for $\mid$ cut-off, $\mathrm{S}$ \\
\hline $\begin{array}{l}\text { Emissions to air: } \mathrm{PM} \\
(\mathrm{g} / \mathrm{kg} \text { tread })\end{array}$ & 12.82 & Particulates, SPM \\
\hline $\begin{array}{l}\text { Emissions to water: COD } \\
(\mathrm{g} / \mathrm{kg} \text { tread })\end{array}$ & 0.091 & COD, chemical oxygen demand \\
\hline $\begin{array}{l}\text { Emissions to water: } \mathrm{NH} 4+-\mathrm{N} \\
(\mathrm{g} / \mathrm{kg} \text { tread })\end{array}$ & 0.01 & Ammonia \\
\hline $\begin{array}{l}\text { Emissions to water: suspended } \\
\text { solid ( } / \mathrm{kg} \text { tread) }\end{array}$ & 0.036 & Suspended solids, unspecified \\
\hline Waste: rubber (kg/kg_tread) & 0.00021 & $\begin{array}{l}\text { District heating incineration (described in Data collection and } \\
\text { Modeling of the Tire's End of Life) }\end{array}$ \\
\hline
\end{tabular}


Table 12 Content in the MK1 diesel, which is assumed to be used in the trucks, and data entries used for each fuel type, based on [42].

\begin{tabular}{lll}
\hline Fuel & Share $($ vol $\%)$ & Modeled as \\
\hline Fossil diesel & $77 \%$ & Diesel $\{$ Europe without Switzerland\}| market for $\mid$ cut-off, S \\
HVO & $17 \%$ & Vegetable oil, refined $\{$ GLO $\} \mid$ market for $\mid$ cut-off, S \\
FAME & $5.5 \%$ & Vegetable oil, refined $\{$ GLO $\} \mid$ market for $\mid$ cut-off, S \\
\hline
\end{tabular}

Table 13: Emissions (g/L) from burning MK1 diesel mix including 4\% FAME and 17\% HVO, based on [43], using Euro VI values when available, otherwise Euro V.

\begin{tabular}{lll}
\hline Emissions to air from MK1 diesel & $\mathrm{g} / \mathrm{l}$ & Modeled as \\
\hline $\mathrm{CO}_{2}$ & 2000 & Carbon dioxide, fossil \\
$\mathrm{CO}$ & 17 & Carbon monoxide \\
$\mathrm{NO}_{\mathrm{x}}$ & 2 & Nitrogen oxides \\
$\mathrm{NMVOC}$ & 0.62 & NMVOC, non-methane volatile organic \\
& & compounds, unspecified origin \\
$\mathrm{SO}_{2}$ & 0.005 & Sulfur dioxide, $\mathrm{SE}$ \\
$\mathrm{N}_{2} \mathrm{O}$ & 0.21 & Dinitrogen monoxide \\
$\mathrm{PM}_{\text {, unspecified }}$ & 0.07 & Particulates, unspecified \\
$\mathrm{CH}_{4}$ & 0.04 & Methane \\
\hline
\end{tabular}

Table 14 Retreading process data and how these inputs/outputs were modeled in this study. Based on primary data from the retreading company.

\begin{tabular}{|c|c|c|c|c|}
\hline & Unit & $\begin{array}{l}\text { Amount as given } \\
\text { (unit } / 23000 \\
\text { retreaded tires) }\end{array}$ & $\begin{array}{l}\text { Amount (unit/ } \\
\text { retreaded tire) }\end{array}$ & Modeled as \\
\hline \multicolumn{5}{|l|}{ Input } \\
\hline Treads & $\mathrm{t}$ & 245 & 0.010652174 & See Table 8 and 11 \\
\hline $\begin{array}{l}\text { Unvulcanized/raw } \\
\text { rubber }\end{array}$ & $\mathrm{t}$ & 25 & 0.001086957 & $\begin{array}{l}\text { Natural rubber: } 61,98 \% \\
\text { Synthetic rubber: } 15,07 \% \\
\text { Carbon black: } 17,50 \% \\
\text { Organic chemicals: } 4,20 \% \\
\text { Zinc oxide: } 1,25 \%\end{array}$ \\
\hline Cement spray & $\mathrm{t}$ & 4.24 & 0.000184348 & Heptane $\{\mathrm{GLO}\} \mid$ market for \\
\hline Rubber sealer & 1 & 15.04 & 0.000653913 & Chemical, organic $\{\mathrm{GLO}\} \mid$ market for \\
\hline Water-based paint & 1 & 2400 & 0.104347826 & $\begin{array}{l}\text { Alkyd paint, white, without solvent, in } 60 \% \\
\text { solution state }\{\mathrm{RER}\} \mid \text { market for alkyd paint, white, } \\
\text { without solvent, in } 60 \% \text { solution stat }\end{array}$ \\
\hline \multicolumn{5}{|r|}{ 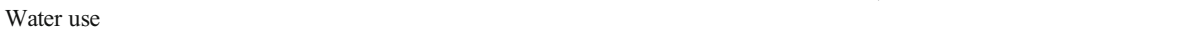 } \\
\hline Water & $\mathrm{m}^{3}$ & 263 & 0.011434783 & $\begin{array}{l}\text { Tap water }\{\text { Europe without Switzerland }\} \mid \\
\text { market for }\end{array}$ \\
\hline Energy use & & & & \\
\hline $\begin{array}{l}\text { Electricity } \\
\text { Emissions to air }\end{array}$ & $\mathrm{kWh}$ & 489619 & 21.28778261 & Electricity, medium voltage $\{\mathrm{SE}\}$ \\
\hline $\begin{array}{l}\text { Fumes from cement } \\
\text { spray step }\end{array}$ & $\mathrm{t}$ & 3.56 & 0.000154783 & Heptane \\
\hline
\end{tabular}




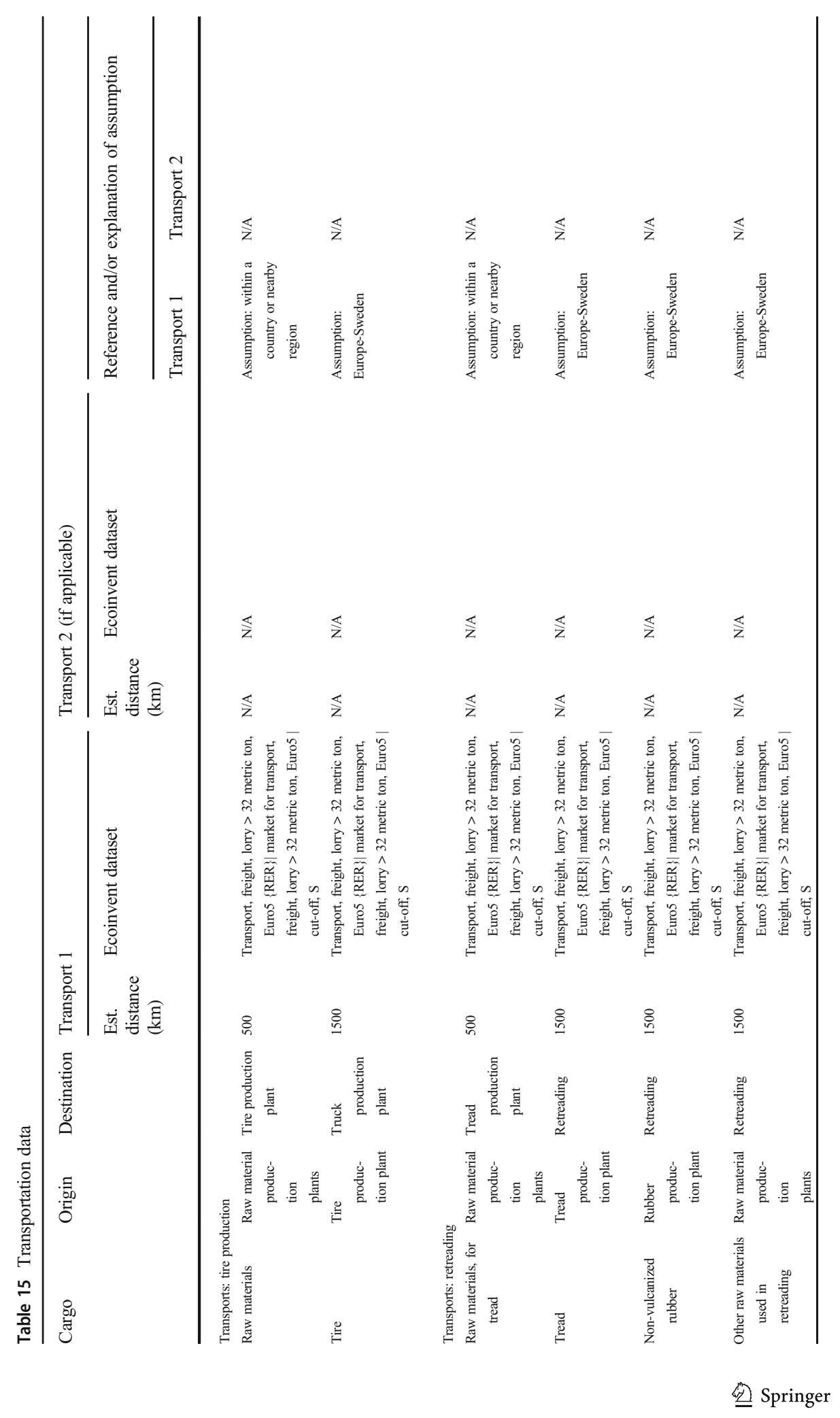




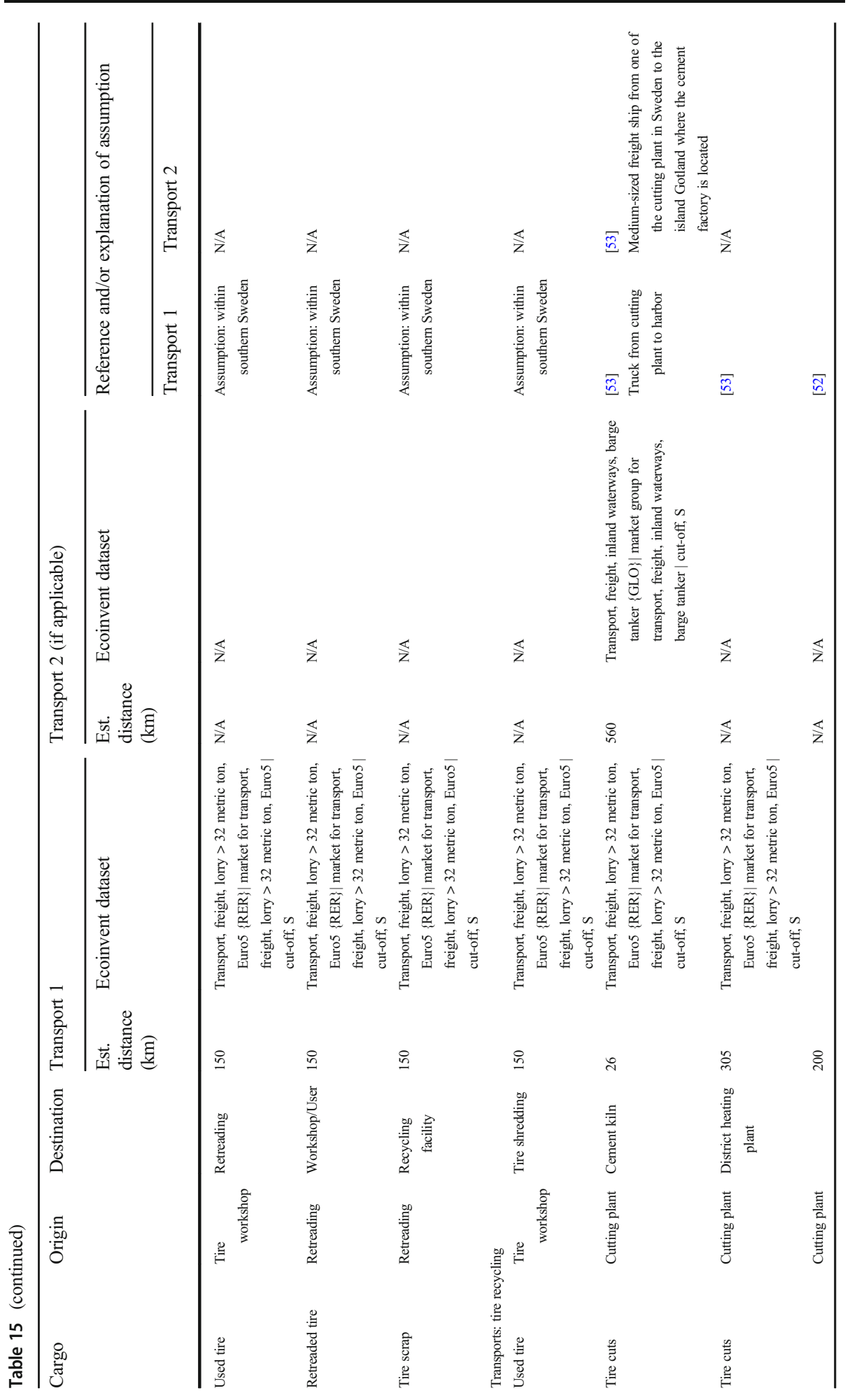




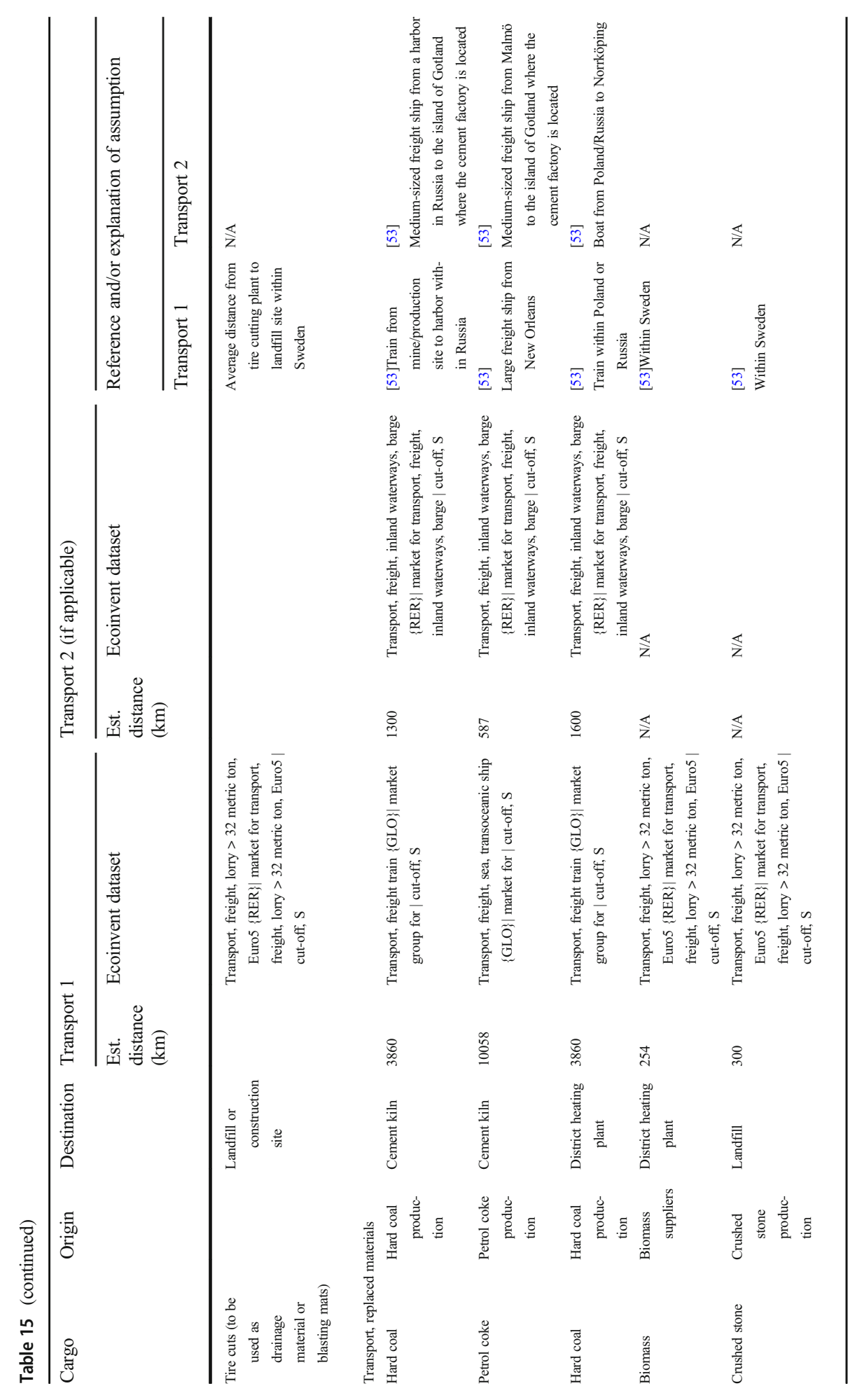




$$
\sqrt{8+\cdots}
$$


Table 16 Modelling data for Tire Pressure Monitoring System (TPMS).

Components and their lifetimes, TPMS

\begin{tabular}{|c|c|c|c|c|}
\hline Component & Count & $\begin{array}{l}\text { Amount/ } \\
\text { count }\end{array}$ & $\begin{array}{l}\text { Modeled as: } \\
\text { Material } \\
\text { ('Selected EcoInvent entry') }\end{array}$ & Lifetime \\
\hline $\begin{array}{l}\text { Sensor unit, including casing, } \\
\text { battery, and magnet }\end{array}$ & $\begin{array}{l}1 \text { per new } \\
\text { tire }^{* *}\end{array}$ & $35 \mathrm{~g}^{*}$ & See per component below & $\begin{array}{l}\text { Limited by battery } \\
\text { lifetime }\end{array}$ \\
\hline Sensor unit casing & $\begin{array}{l}1 \text { per sensor } \\
\text { unit }^{* *}\end{array}$ & $5 \mathrm{~g}^{* * *}$ & $\begin{array}{l}\text { Polyurethane* } \\
\text { (Polyurethane, rigid foam } \\
\quad\{\text { RER }\} \text { ) }\end{array}$ & - \\
\hline Sensors & $\begin{array}{l}1 \text { per sensor } \\
\text { unit }^{* *}\end{array}$ & $5 \mathrm{~g}^{* * *}$ & $\begin{array}{l}\text { Unspecified electronics } \\
\text { passive } \text { e*** }^{*} \\
\text { ('Electronic component, } \\
\text { passive, unspecified } \\
\{\mathrm{GLO}\})\end{array}$ & - \\
\hline Battery & $\begin{array}{l}1 \text { per sensor } \\
\text { unit }^{* *}\end{array}$ & $5 \mathrm{~g}^{* * * *}$ & $\begin{array}{l}\text { Li-ion battery }{ }^{* * *} \\
\text { ('Battery cell, Li-ion } \\
\quad\{\mathrm{GLO}\})\end{array}$ & $3-5$ years ${ }^{* *}$ \\
\hline Magnet & $\begin{array}{l}1 \text { per sensor } \\
\text { unit }^{* *}\end{array}$ & $20 \mathrm{~g}^{* * * *}$ & $\begin{array}{l}\text { NdFeB } \\
\text { (Permanent magnet, for } \\
\quad \text { electric motor }\{\mathrm{GLO}\})\end{array}$ & - \\
\hline $\begin{array}{l}\text { Gateway with } 4 \mathrm{G}, 3 \mathrm{G} \text {, and } 2 \mathrm{G} \\
\text { connection, including casing }\end{array}$ & 1 per truck $^{* *}$ & $200 \mathrm{~g}^{*}$ & See per component below & $\begin{array}{l}\text { At least as long as } \\
\text { sensor unit } \\
\text { lifetime }\end{array}$ \\
\hline Electronics & 1 per gateway & $100 \mathrm{~g}^{* * *}$ & $\begin{array}{l}\text { Unspecified electronics } \\
\text { active }{ }^{* * *} \\
\text { ('Electronic component, } \\
\text { active, unspecified } \\
\{\mathrm{GLO}\} \text { ) }\end{array}$ & - \\
\hline Casing & $\begin{array}{l}1 \text { per } \\
\text { gateway }\end{array}$ & $100 \mathrm{~g}^{* * * *}$ & $\begin{array}{l}\text { Nylon* } \\
\text { (Nylon 6-6 }\{\mathrm{GLO}\} \text { ) }\end{array}$ & - \\
\hline Cable & 1 per truck $^{* *}$ & $\begin{array}{l}14^{* *} \\
\text { me- } \\
\text { ters }\end{array}$ & $\begin{array}{l}\text { Unspecified cable } \\
\text { material } \\
\text { ('Cable, unspecified } \\
\{\text { GLO }\})\end{array}$ & $\begin{array}{l}\text { At least as long as } \\
\text { sensor unit } \\
\text { lifetime }{ }^{* * *}\end{array}$ \\
\hline
\end{tabular}

\footnotetext{
* Direct communication with the TPMS manufacturer

** Technical datasheet from the TPMS manufacturer [29]

**** Estimation by authors
} 
Table 17 Modeling data for piezoelectric sensor system

\begin{tabular}{|c|c|c|c|c|}
\hline Component & Count & $\begin{array}{l}\text { Amount/ } \\
\text { count }\end{array}$ & $\begin{array}{l}\text { Modeled as: } \\
\text { material } \\
\text { ('Selected EcoInvent entry') }\end{array}$ & Lifetime \\
\hline Sensor unit & 1 & $50^{* *}$ & See per component below & Same as tire ${ }^{\text {*** }}$ \\
\hline Antenna & $\begin{array}{l}2^{*} \text { per sensor } \\
\quad \text { unit }\end{array}$ & $5 \mathrm{~g}^{* *}$ & $\begin{array}{l}\text { Copper }^{* *} \\
\text { (Copper }\{\mathrm{GLO}\} \mid \text { market for) }\end{array}$ & - \\
\hline $\begin{array}{l}\text { Piezoelectric } \\
\text { film sensor }\end{array}$ & $\begin{array}{l}1^{*} \text { per sensor } \\
\quad \text { unit }\end{array}$ & $5 \mathrm{~g}^{* * *}$ & $\begin{array}{l}\text { Unspecified electronics passive }{ }^{* *} \\
\text { (Electronic component, passive, unspecified } \\
\quad\{\mathrm{GLO}\} \text { ) }\end{array}$ & - \\
\hline Casing & $\begin{array}{l}1^{* * *} \text { per } \\
\text { sensor } \\
\quad \text { unit }\end{array}$ & $40 \mathrm{~g}^{* *}$ & $\begin{array}{l}\text { Polyurethane }{ }^{* *} \\
\text { (Polyurethane, rigid foam }\{\mathrm{RER}\} \mid \text { market for } \\
\text { polyurethane, rigid foam) }\end{array}$ & - \\
\hline Gateway & $1^{*}$ per truck & $300 \mathrm{~g}^{* *}$ & See per component below & $\begin{array}{l}\text { At least as long as } \\
\text { sensor unit }^{* *}\end{array}$ \\
\hline Casing & $\begin{array}{l}1 \text { per } \\
\text { gateway }\end{array}$ & $150 \mathrm{~g}^{* *}$ & $\begin{array}{l}\text { Polyurethane }{ }^{* *} \\
\text { (Polyurethane, rigid foam }\{R E R\} \mid \text { market for } \\
\quad \text { polyurethane, rigid foam) }\end{array}$ & - \\
\hline Electronics & $\begin{array}{l}1 \text { per } \\
\text { gateway }\end{array}$ & $150 \mathrm{~g}^{* * *}$ & $\begin{array}{l}\text { Unspecified electronics active }{ }^{\text {*** }} \\
\text { (Electronic component, active, unspecified }\{\mathrm{GLO}\} \text { ) }\end{array}$ & - \\
\hline Cable & 1 per truck & 14 meters** & $\begin{array}{l}\text { Unspecified cable material }{ }^{* *} \\
\text { (Cable, unspecified }\{\mathrm{GLO}\} \text { ) }\end{array}$ & $\begin{array}{l}\text { At least as long as } \\
\text { sensor unit }^{* *}\end{array}$ \\
\hline
\end{tabular}

*As reported in [23]

** Estimation by authors

Table 18 Modelling data for RFID tag

\begin{tabular}{|c|c|c|c|c|}
\hline Component & Count & $\begin{array}{l}\text { Weight per } \\
\text { count }\end{array}$ & $\begin{array}{l}\text { Modeled as: } \\
\text { material } \\
\text { ('Selected ecoinvent entry') }\end{array}$ & Lifetime \\
\hline RFID tag & $\begin{array}{l}1 \text { per new tire and } 1 \text { per added } \\
\text { tread }\end{array}$ & $10 \mathrm{~g}^{* * *}$ & See per component below & $\begin{array}{c}\text { Same as } \\
\text { tire }^{* * *}\end{array}$ \\
\hline Antenna & 1 per RFID tag & $1.22 \mathrm{~g}^{*}$ & See per component below & - \\
\hline Substrate & 1 per antenna & $0.98 \mathrm{~g}^{*}$ & $\begin{array}{l}\text { Plastic film* } \\
\text { (Extrusion, plastic film }\{\mathrm{GLO}\} \text { ) }\end{array}$ & - \\
\hline Ink & 1 per antenna & $0.24 \mathrm{~g}^{*}$ & $\begin{array}{l}\text { Silver ink* } \\
\text { (silver }\{\mathrm{GLO}\} \text { ) }\end{array}$ & - \\
\hline Chip & 1 per RFID tag & $4.4 \mathrm{~g}^{* *}$ & $\begin{array}{l}\text { Unspecified electronics passive }{ }^{* *} \\
\text { (Electronic component, passive, unspecified } \\
\quad\{\mathrm{GLO}\} \text { ) }\end{array}$ & - \\
\hline Casing & 1 per RFID tag & $4.4 \mathrm{~g}^{* *}$ & $\begin{array}{l}\text { Polyurethane }{ }^{* *} \\
\text { (Polyurethane, rigid foam }\{R E R\} \text { ) }\end{array}$ & - \\
\hline
\end{tabular}

\footnotetext{
* As reported in [8]

*** Estimation by authors
} 
Table 19 Data used to model energy requirements of the added technology in the IoT scenario

\begin{tabular}{|c|c|c|c|c|}
\hline & Assumption & How total was calculated & Unit & Modeled as \\
\hline $\begin{array}{l}\text { Energy } \\
\text { requirements } \\
\text { data collection } \\
\text { by sensors }\end{array}$ & $1 \mathrm{~W}$ typical power* & $1 / 1000[\mathrm{~kW}] \cdot$ total hours of tire use $[\mathrm{h}]$ & $\mathrm{kWh}$ & $\begin{array}{l}\text { (Electricity, } \\
\text { low voltage } \\
\{\mathrm{SE}\})\end{array}$ \\
\hline $\begin{array}{l}\text { Gateway energy } \\
\text { requirements for } \\
\text { data transfer }\end{array}$ & $\begin{array}{l}\text { Sends data every } 2 \\
\text { minutes via } 4 \mathrm{G} \\
\text { LTE network }\end{array}$ & $\begin{array}{l}1 / 2^{*}[\text { transfers } / \text { minute }] \cdot 4^{* *}[\text { bytes/transfer }] \\
10^{-9}[\mathrm{~GB} \text { per byte }] \cdot 0.3^{* * * *}[\mathrm{kWh} / \mathrm{GB}] \\
\text { total minutes of tire use }[\mathrm{min}]\end{array}$ & $\mathrm{kWh}$ & $\begin{array}{l}\text { (Electricity, } \\
\quad \text { low voltage } \\
\{\mathrm{SE}\})\end{array}$ \\
\hline $\begin{array}{l}\text { Cloud-side energy } \\
\text { requirements }\end{array}$ & $\begin{array}{l}\text { Sends data every } 2 \\
\text { minutes* } \\
4 \text { bytes per } \\
\text { transfer** }\end{array}$ & Eq. A. $1^{* * * *}$ & $\mathrm{kWh}$ & $\begin{array}{l}\text { (Electricity, } \\
\text { medium } \\
\text { voltage } \\
\{\mathrm{SE}\})\end{array}$ \\
\hline
\end{tabular}

* Technical datasheet from TPMS manufacturer [29]

** Estimation by authors

${ }^{* * *}$ As reported in [45]

${ }^{* * * *}$ As reported in [14]

$P_{\mathrm{st}, \mathrm{SR}} \quad$ is the power consumption of a 'content server', estimated to $0.225^{* * * *}[\mathrm{~kW}]$.

$C_{\text {st, SR }}$ is the capacity of the content server, estimated to $800^{* * * * *}$ [Mbits/s].

$P_{\mathrm{SD}} \quad$ is the power consumption of the hard disk arrays, estimated to $4.9^{* * * *}[\mathrm{~kW}]$.

$B_{\mathrm{SD}} \quad$ is the capacity of the hard disk arrays, estimated to $604.8^{* * * *}$ [Tbits].

Open Access This article is licensed under a Creative Commons Attribution 4.0 International License, which permits use, sharing, adaptation, distribution and reproduction in any medium or format, as long as you give appropriate credit to the original author(s) and the source, provide a link to the Creative Commons licence, and indicate if changes were made. The images or other third party material in this article are included in the article's Creative Commons licence, unless indicated otherwise in a credit line to the material. If material is not included in the article's Creative Commons licence and your intended use is not permitted by statutory regulation or exceeds the permitted use, you will need to obtain permission directly from the copyright holder. To view a copy of this licence, visit http://creativecommons.org/licenses/by/4.0/.

\section{References}

1. Ingemarsdotter E, Jamsin E, Kortuem G, Balkenende R (2019) Circular strategies enabled by the Internet of Things - a framework and analysis of current practice. Sustainability 11:5689. https://doi.org/10.3390/ su11205689

2. Alcayaga A, Wiener M, Hansen EG (2019) Towards a framework of smart-circular systems: an integrative literature review. J Clean Prod 221:622-634. https://doi.org/10.1016/j.jclepro.2019.02.085

3. Bressanelli G, Adrodegari F, Perona M, Saccani N (2018) Exploring how usage-focused business models enable circular economy through digital technologies. Sustainability 10:639. https://doi.org/10.3390/ su10030639

4. Ellen MacArthur Foundation (2016) Intelligent Assets: Unlocking the Circular Economy Potential. UK, London https://www.ellenmacarthurfoundation.org/publications 
5. Linder M, Boyer RHW, Dahllöf L, Vanacore E, Hunka A (2020) Product-level inherent circularity and its relationship to environmental impact. J Clean Prod 260:121096. https://doi.org/10.1016/j.jclepro.2020. 121096

6. Nussholz JLK (2019) Circular business model design: a checklist for creating environmental benefits. https://doi.org/10.13140/RG.2.2.14624.12808

7. Böckin D, Willskytt S, André H, Tillman AM, Ljunggren Söderman M (2020) How product characteristics can guide measures for resource efficiency — a synthesis of assessment studies. Resour Conserv Recycl 154: 104582. https://doi.org/10.1016/j.resconrec.2019.104582

8. Kanth RK, Liljeberg P, Tenhunen H, Tenhunen H, Zheng LR, Amin Y, Kumar H (2015) Study on sustainability and life cycle assessment of RFID antenna. In: Environmental Engineering and Computer Application-Proceedings of the International Conference on Environmental Engineering and Computer Application. ICEECA 2014, Hong Kong, pp 369-372

9. Bonvoisin J, Lelah A, Mathieux F, Brissaud D (2012) An environmental assessment method for wireless sensor networks. J Clean Prod 33:145-154. https://doi.org/10.1016/j.jclepro.2012.04.016

10. Malmodin J, Lunden D, Nilsson M, Andersson G (2012) LCA of data transmission and IP core networks. In: Proceedings of Electronics Goes Green 2012+. ECG, Berlin

11. Scharnhorst W (2006) Life cycle assessment of mobile telephone networks, with focus on the end-of-life phase. $\mathrm{PhD}$ thesis. École Polytechnique Fédérale de Lausanne.

12. Shehabi A, Smith SJ, Masanet E, Koomey J (2018) Data center growth in the United States: decoupling the demand for services from electricity use. Environ Res Lett 13:124030. https://doi.org/10.1088/1748-9326/ aaec9c

13. Knottnerus A (2019) A methodology for energy analysis of high performance cloud users. MSc thesis. Leiden University and TU Delft, Leiden

14. Baliga BJ, Ayre RWA, Hinton K, Tucker RS (2010) Green cloud computing: balancing energy in processing, storage and transport. Proc IEEE 99:149-167. https://doi.org/10.1109/JPROC.2010.2060451

15. Chen F, Schneider JG, Yang Y, Grundy J, He Q (2012) An energy consumption model and analysis tool for Cloud computing environments. In: 1st International Workshop on Green and Sustainable Software, GREENS 2012 - Proceedings. IEEE, Zurich, pp 45-50

16. Uchechukwu A, Li K, Shen Y (2014) Energy consumption in cloud computing data centers. Int J Cloud Comp Serv Sci 3:31. https://doi.org/10.11591/closer.v3i3.6346

17. Lelah A, Mathieux F, Brissaud D (2011) Contributions to eco-design of machine-to-machine product service systems: the example of waste glass collection. J Clean Prod 19:1033-1044. https://oi.org/10. 1016/j.jclepro.2011.02.003

18. Bonvoisin J, Lelah A, Mathieux F, Brissaud D (2014) An integrated method for environmental assessment and ecodesign of ICT-based optimization services. J Clean Prod 68:144-154. https://doi.org/10.1016/j. jclepro.2014.01.003

19. Kumar T, Mani M (2017) Life cycle assessment (LCA) to assess energy neutrality in occupancy sensors. In: Chakrabarti A, Chakrabarti D (eds) Research into Design for Communities, Volume 2. ICoRD 2017. Smart Innovation, Systems and Technologies, vol 66. Springer, Singapore. https://doi.org/10.1007/978-981-103521-0 9

20. Dekoninck E, Barbaccia F (2019) Streamlined assessment to assist in the design of Internet-of-Things (IoT) enabled products: a case study of the smart fridge. In: Proceedings of the International Conference on Engineering Design. ICED, Delft, pp 3721-3730. https://doi.org/10.1017/dsi.2019.379

21. Yuli M, Puig R, Fuentes MA, Civancik-Uslu D, Capilla M (2019) Eco-innovation in garden irrigation tools and carbon footprint assessment. Int J Environ Sci Technol 16:2937-2950. https://doi.org/10.1007/s13762018-1937-y

22. Diener D, Nyström T, Mellquist A-C, Jonasson C, Andersson S (2019) The legend of the circular tire: creating a vision for a more resource productive tire business ecosystem. In: Proceedings of the Product Lifetimes and the Environment (PLATE) Conference. Germany, Berlin, pp 18-20

23. Mellquist A-C, Johansson C, Jonasson C, Diener D, Norefjäll F, Linder M, Altmann P, Nyström T (2020) Circular economy in a business eco-system: integrated sensors and new recycling technology for heavy vehicle tyres. RISE AB, Gothenburg Available from: https://www.ri.se/en/what-we-do/projects/circularbusinessecosystem-sensors-and-recycling-heavy-vehicle-tyres

24. Andersson S, Diener D (2019) Life cycle assessment of resource effectiveness in a business ecosystem of heavy-duty truck tires. IVL and RISE sustainable business. Available from: https://www.ri.se/en/what-wedo/projects/circular-businessecosystem-sensors-and-recycling-heavy-vehicle-tyres.

25. International Organization for Standardization (2006) ISO 14040:2006 Environmental Management-Life Cycle Assessment-Principles and Framework. Switzerland, Geneva

26. Klöpffer W, Grahl B (2014) Life Cycle Assessment (LCA): A Guide to Best Practice. John Wiley \& Sons, Weinheim 
27. Pré Consultants B.V. (2020) SimaPro. https://simapro.com/ .

28. Ecoinvent (2018) Ecoinvent:3.5 https://www.ecoinvent.org/database/older-versions/ecoinvent-35/ ecoinvent-35.html.

29. El-watch (2019) The Neuron Tyre Health System. https://www.el-watch.com/wp-content/uploads/2019/11/ THS-Facts-EN-08.pdf. .

30. Huijbregts M, Steinmann ZJN, Elshout PMFM, Stam G, Verones F, Vieira MDM, Zijp M, van Zelm R (2016) ReCiPe 2016 - a harmonized life cycle impact assessment method at midpoint and endpoint level. Report I. Characterization (RIVM Report 2016- 0104)

31. RIVM Recipe 2008 - ReCiPe version 1.11 (Endpoints). Available from: https://www.rivm.nl/documenten/ 8recipe111endpoints

32. Guinée J, Heijungs R, Frischknecht R (2019) Multi-functionality in life cycle inventory analysis: approaches and solutions. In: Klöpffer W, Curran MA (eds) LCA Compendium-The Complete World of Life Cycle Assessment, Chap. 4: Life Cycle Inventory Analysis (Arvidsson R., Ciroth A. (eds)). Springer, Dordrecht

33. Sun X, Liu J, Hong J, Lu B (2016) Comparative life cycle assessment of Chinese radial passenger vehicle tire. Int J Life Cycle Assess 21:1749-2445. https://doi.org/10.4028/www.scientific.net/MSF.898.2432

34. Michelin (2019) Different life stages of Michelin truck tyres. https://www.michelin.in/truck-bus-tyres/ retread.

35. Boustani A, Sahni S, Gutowski T, Graves S (2010) Tire remanufacturing and energy savings. Environmentally Benign Manufacturing Laboratory, Sloan School of Management Available from: http:// web.mit.edu/ebm/www/Publications/MITEI-1-h-2010.pdf

36. Pehlken A, Roy G (2006) Identifying LCA-elements in scrap tire recycling. WIT Trans Ecol Environ 92: 325-333. https://doi.org/10.2495/WM060351

37. Brigdestone (2012) Total Tyre Life Brochure. https://www.bridgestone.co.uk/truck-and-bus/downloads. .

38. Gutowski TG, Sahni S, Boustani A, Graves SC (2011) Remanufacturing and energy savings. Environ Sci Technol 45:4540-4547. https://doi.org/10.1021/es102598b

39. Krömer S, Kreipe E, Reichenbach D, Stark R (1999) Life cycle assessment of a car tire. Continental AG. Available from: https://www.continental.com/resource/blob/47500/b64cfd62d7c37b31e0141cb618756f86/ oekobilanz-en-data.pdf.

40. EU (2020) Regulation (EU) 2020/740 on the labelling of tyres with respect to fuel efficiency and other parameters. The European Parliament and the Council of the European Union.

41. Volvo Trucks (2020) Tyres and how they impact fuel consumption. https://content.volvotrucks.com/areyour-trucks-tyres-causing-unnecessary-fuel-consumption. .

42. Energimyndigheten (2019) Drivmedel:2018 Available from: www.energimyndigheten.se/statistik

43. Hallberg L, Rydberg T, Bolin L, Dahllöf L, Mikaelsson H, Iverfeldt E, Tivander J (2013) Well-to-wheel LCI data for fossil and renewable fuels on the Swedish market. f3, the Swedish Knowledge Center for Renewable Transport Fuels. Available from: www.f3centre.se.

44. RFID4U (2020) Dig deep — construction of RFID tags. https://rfid4u.com/dig-deepconstruction-of-rfid-tags.

45. Pihkola H, Hongisto M, Apilo O, Lasanen M (2018) Evaluating the energy consumption of mobile data transfer-from technology development to consumer behaviour and life cycle thinking. Sustainability 10: 2494. https://doi.org/10.3390/su10072494

46. Maria DB (2019) Data type storage requirements. https://mariadb.com/kb/en/data-type-storagerequirements/.

47. Saidani M, Yannou B, Leroy Y, Cluzel F (2018) Heavy vehicles on the road towards the circular economy: analysis and comparison with the automotive industry. Resour Conserv Recycl 135:108-122. https://doi. org/10.1016/j.resconrec.2017.06.017

48. European Environmental Agency (2020) Indicator assessment: use of renewable energy for transport in Europe. https://www.eea.europa.eu/data-and-maps/indicators/use-of-cleaner-and-alternative-fuels-2/ assessment

49. Ragnsells Däckåtervinning AB (2019) Däckets väg i återvinningsprocessen. https://www. ragnsellstyrerecycling.com/article-startpage/dackets-vag-i-atervinningsprocessen/.

50. Ragnsells Däckåtervinning $\mathrm{AB}$ (2019) Ragn-Sells stänger produktionen av granulat på Heljestorp. https:// www.ragnsells.se/om-ragn-sells/pressrum/\#/pressreleases/ragn-sells-staenger-produktionen-av-granulatpaa-heljestorp-2908828.

51. SDAB (2019) Uttjänta däck har mycket kvar att ge. https://www.sdab.se/newsletter/news-mars-2019/ uttjaenta-daeck-har-mycket-kvar-att-ge/.

52. Alongi Skenhall S, Hallberg L, Rydberg T (2012) Livscykelanalys på återvinning av däck - Jämförelser mellan däckmaterial och alternativa material i konstgräsplaner, dräneringslager och ridbanor. IVL Svenska Miljöinstitutet. Available from: https://www.sdab.se/media/1066/lca_livscykelanalys.pdf. 
53. Hallberg L, Stromberg K, Rydberg T, Eriksson E (2006) Comparative life cycle assessment of the utilisation of used tyres. CIT Ekologik AB \& IVL Svenska Miljöinstitutet AB.

54. Cementa (2018) Färdplan cement för ett klimatneutralt betongbyggande. Cementa AB. Available from: https://www.cementa.se/sv/fardplancement.

55. Eon (2011) Med värme från Händelö kraftvärmeverk.

\section{Affiliations}

\section{Emilia Ingemarsdotter ${ }^{1} \cdot$ Derek Diener $^{2} \cdot$ Simon Andersson $^{3} \cdot$ Christian Jonasson $^{2} \cdot$ Ann-Charlotte Mellquist ${ }^{2} \cdot$ Thomas Nyström $^{2} \cdot$ Ella Jamsin $^{1} \cdot$ Ruud Balkenende $^{1}$}

1 Faculty of Industrial Design Engineering, Delft University of Technology, Landbergstraat 15, 2628 CE Delft, The Netherlands

2 Research Institutes of Sweden (RISE), Lindholmspiren 7a, 41756 Göteborg, Sweden

3 Svenska Miljöinstitutet (IVL), Aschebergsgatan 44, 41133 Göteborg, Sweden 